\title{
Spiciness Anomalies in the Upper South Indian Ocean
}

\author{
Motoki NAgURA AND SHINYA KOUKETSU \\ Japan Agency for Marine-Earth Science and Technology, Yokosuka, Kanagawa, Japan
}

(Manuscript received 16 March 2018, in final form 11 June 2018)

\begin{abstract}
This study investigates an isopycnal temperature/salinity $T / S$, or spiciness, anomaly in the upper south Indian Ocean for the period from 2004 to 2015 using observations and reanalyses. Spiciness anomalies at about $15^{\circ} \mathrm{S}$ on $24-26 \sigma_{\theta}$ are focused on, whose standard deviation is about $0.1 \mathrm{psu}$ in salinity and $0.25^{\circ} \mathrm{C}$ in temperature, and they have a contribution to isobaric temperature variability comparable to thermocline heave. A plausible generation region of these anomalies is the southeastern Indian Ocean, where the $25 \sigma_{\theta}$ surface outcrops in southern winter, and the anticyclonic subtropical gyre advects subducted water equatorward. Unlike the Pacific and Atlantic, spiciness anomalies in the upper south Indian Ocean are not $T / S$ changes in mode water, and meridional variations in SST and sea surface salinity in their generation region are not density compensating. It is possible that this peculiarity is owing to freshwater originating from the Indonesian Seas. The production of spiciness anomalies is estimated from surface heat and freshwater fluxes and the surface $T / S$ relationship in the outcrop region, based on several assumptions including the dominance of surface fluxes in the surface $T / S$ budget and effective mixed layer depth proposed by Deser et al. The result agrees well with isopycnal salinity anomalies at the outcrop line, which indicates that spiciness anomalies are generated by local surface fluxes. It is suggested that the Ningaloo Niño and El Niño-Southern Oscillation lead to interannual variability in surface heat flux in the southeastern Indian Ocean and contribute to the generation of spiciness anomalies.
\end{abstract}

\section{Introduction}

The primal process that causes isobaric temperature variability in the ocean interior is thermocline heaving. Depression (or elevation) of the thermocline leads to warming (cooling) at a fixed level, which accompanies variability in density and is related to wave dynamics. Another process that causes interior temperature variability is variations in spiciness (e.g., Bindoff and McDougall 1994; Arbic and Owens 2001), that is, changes in the temperature/salinity $T / S$ property of a water mass with variability in temperature $T$ and salinity $S$ compensating for each other in terms of density. Spiciness variations do not accompany density variability and are advected by the mean current as a passive tracer. Previous studies pointed out that the above two processes are related to climate variability at different time scales. The period of wave motion is usually shorter than the time scale of mean current advection at low latitudes. Thermocline heave is more directly related to climate variability on interannual time scales near the equator (e.g., Schopf and Suarez 1988),

\footnotetext{
Corresponding author: Motoki Nagura, nagura@jamstec.go.jp
}

whereas advection of the spiciness anomaly from middle to low latitudes can be related to decadal and multidecadal variability (Gu and Philander 1997; Schneider 2000; Giese et al. 2002; Luo et al. 2005; Tatebe et al. 2013; Kouketsu et al. 2017).

Much effort has been devoted to investigate spiciness anomalies in the upper thermocline of the Pacific Ocean, seeking a mechanism of decadal/multidecadal variability in El Niño-Southern Oscillation (ENSO). In the Pacific, water mass subducts in the midlatitudes and upwells near the equator ( $\mathrm{Lu}$ and McCreary 1995; Johnson and McPhaden 1999), and the inflow from the Southern Hemisphere to the equator is larger in volume than that from the Northern Hemisphere (Blanke and Raynaud 1997; Lu et al. 1998; Rodgers et al. 2003; Fukumori et al. 2004; Goodman et al. 2005; Grenier et al. 2011). Consistently, spiciness anomalies generated in the South Pacific Ocean on the surfaces of potential density $\left(\sigma_{\theta}\right)$ ranging from 24.5 to 25.5 flow into the equatorial region and lead to decadal/multidecadal variability in equatorial temperature (Kessler 1999; Schneider 2000; Giese et al. 2002; Yeager and Large 2004; Luo et al. 2005; Nonaka and Sasaki 2007; Kolodziejczyk and Gaillard 2012; Li et al. 2012; Tatebe et al. 2013; 
O'Kane et al. 2014). Spiciness anomalies are also generated and migrate equatorward in the North Pacific Ocean (Deser et al. 1996; Schneider et al. 1999; Ren and Riser 2010; Sasaki et al. 2010; Kolodziejczyk and Gaillard 2012), but their fate is unclear. A numerical model study showed that they reach the equator and contribute to decadal temperature variability (Schneider 2000), whereas observational studies claimed that anomalies are dissipated before reaching the equator (Schneider et al. 1999; Sasaki et al. 2010). A similar migration of spiciness anomalies is found in the Atlantic Ocean on 25-26 $\sigma_{\theta}$ (Lazar et al. 2001; Laurian et al. 2006; Qu et al. 2016).

In contrast to the Pacific and Atlantic Oceans, there is only one study to our knowledge that examined spiciness anomalies in the upper pycnocline of the Indian Ocean. Li and Wang (2015) used a dataset based on Argo float observations and examined spatial and temporal variations of spiciness anomalies in the Indian Ocean focusing on the $24-25 \sigma_{\theta}$ surfaces. They found a large amplitude of anomalies in the southeastern part of the Arabian Sea, along $10^{\circ}$ and $15^{\circ} \mathrm{S}$ in the south Indian Ocean. Among them, anomalies along $10^{\circ} \mathrm{S}$ were accounted for by advection of interior flow. On $24-25 \sigma_{\theta}$, saline water originated from the Arabian Sea meets freshwater advected from the Indonesian Seas at about $10^{\circ} \mathrm{S}$. Variations in meridional currents related to Rossby waves cause the meridional excursion of this salinity front, resulting in spiciness anomalies. For anomalies along $15^{\circ} \mathrm{S}, \mathrm{Li}$ and Wang showed that they spread to the west at a similar speed to the mean current, the westward South Equatorial Current (SEC), which was a few times slower than the typical phase speed of Rossby waves. Anomalies at this latitude could not be attributed to interior flow advection associated with Rossby waves, and their generation mechanism was unknown.

In this study, we examine spiciness anomalies in the south Indian Ocean on $25 \sigma_{\theta}$ along $15^{\circ} \mathrm{S}$, focusing on their generation mechanism. Spiciness anomalies in the Arabian Sea discovered by Li and Wang (2015) are also worth a detailed study, but here we focus on the south Indian Ocean, because the main subduction region is in the Southern Hemisphere in the Indian Ocean (e.g., Schott et al. 2009).

In the Pacific and Atlantic Oceans, spiciness anomalies are generated in the formation region of mode water, where $T$ and $S$ variations near the surface tend to be density compensating (Johnson 2006). In such a region, a water of higher spiciness can be replaced with that of lower spiciness (or vice versa) by various processes without much change in density, leading to a spiciness anomaly in subducted water. For example, enhancement of vertical mixing near the surface injects surface saline water to subsurface and generates a positive spiciness anomaly, when $T$ and $S$ tend to be density compensating in the vertical direction (Yeager and Large 2004; Kolodziejczyk and Gaillard 2012, 2013; Kolodziejczyk et al. 2015). Advection by surface Ekman currents (Rintoul and England 2002) and/or the migration of the outcrop line of a density surface (Nonaka and Sasaki 2007; Laurian et al. 2009) also cause spiciness variations, when surface $T$ and $S$ tend to be density compensating in the meridional direction. On the other hand, as is shown below, surface $T$ and $S$ do not tend to be density compensating in the generation region of spiciness anomalies in the south Indian Ocean. Thus, the above mentioned mechanisms are inapplicable to our case. We propose a mechanism that is suitable to our case in this study.

This paper is organized as follows. Section 2 describes datasets we used. Section 3 describes spatial and temporal patterns of spiciness anomalies, which is an extension of Li and Wang's (2015) work. Section 4 discusses the generation mechanism. Section 5 seeks relevance to climate modes. Section 6 summarizes the main results.

\section{Data}

\section{a. In situ hydrographic observations}

We obtained in situ $T / S$ observations from conductivitytemperature-depth (CTD) and profile float (PFL) data from the World Ocean Database (WOD) archive (Boyer et al. 2013) for the region from $50^{\circ} \mathrm{S}$ to $30^{\circ} \mathrm{N}$ and from $30^{\circ}$ to $120^{\circ} \mathrm{E}$. First, we discarded data if the WOD quality flag was not 0 , for "accepted value." Second, data were eliminated if they deviated from the mean by more than three standard deviations. The mean and standard deviation were obtained from the World Ocean Atlas 2013 on a $5^{\circ} \times 5^{\circ}$ grid (Locarnini et al. 2013; Zweng et al. 2013). Third, we discarded erroneous data manually. These checks removed $16 \%$, $0.5 \%$, and $1.2 \%$ of the data, respectively. The total number of profiles is 221614 . Observations are mostly confined to the upper $2000 \mathrm{~m}$, which is owing to the dominant contribution from Argo floats. Nagura and McPhaden (2018) described the details of density of these in situ observations.

We interpolated $T / S$ and pressure data onto $\sigma_{\theta}$ surfaces using Fofonoff and Millard's (1983) equation of the state. The resulting $T / S$ and pressure data on isopycnals were objectively mapped on a $1^{\circ} \times 1^{\circ}$ grid for each calendar year, using the method of Bretherton et al. (1976) and assuming a Gaussian covariance function. We used decorrelation scales of $6^{\circ}$ in longitude and $3^{\circ}$ in latitude. A total of 1000 profiles with the highest weights were used for estimates at each grid. 
(a) $30^{\circ} \mathrm{S}-\mathrm{Eq}, 50^{\circ}-100^{\circ} \mathrm{E}$

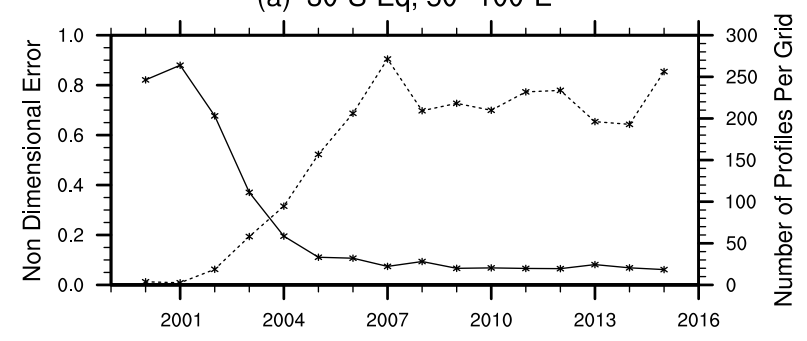

(b) 2003

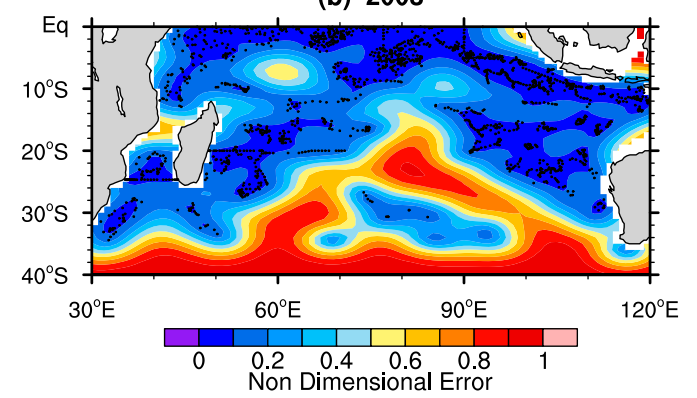

(c) 2010

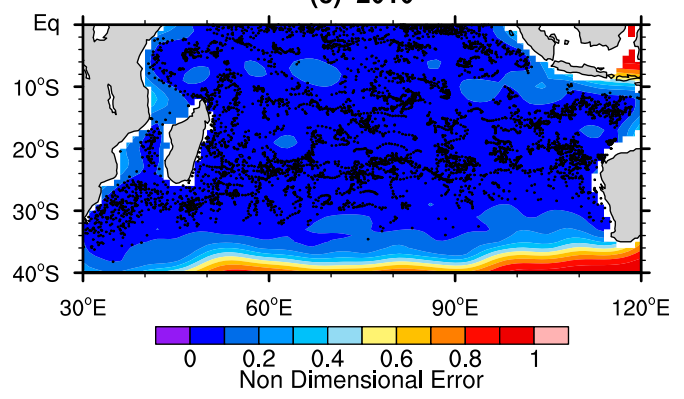

FIG. 1. (a) The time series for nondimensional error on $25 \sigma_{\theta}$ (solid line) and the number of $T / S$ profiles within the decorrelation scale around each grid (dotted line) averaged over the south Indian Ocean $\left(30^{\circ} \mathrm{S}-0^{\circ}, 50^{\circ}-100^{\circ} \mathrm{E}\right)$. (b) Nondimensional error (colors) and data points (dots) on $25 \sigma_{\theta}$ in 2003. (c) As in (b), but for 2010.

This mapping produced yearly estimates of $T, S$, and pressure on density surfaces.

Error for objective mapping is defined as the deviation of the estimate from the true value, which can be estimated from the variance of input data, assumed covariance function, and the distance between grid point and data points [Eq. (10) of Bretherton et al. (1976)]. By replacing the variance of data with unity, a nondimensional error can be calculated, which represents only the density of observations irrespective of the data variance. It ranges from 0 to unity and tends to be large (small) in a region with sparse (dense) observations. A nondimensional error of unity roughly corresponds to a dimensional error of $0.1-0.3 \mathrm{psu}$ on $25 \sigma_{\theta}$ in our case. The error on $25 \sigma_{\theta}$ averaged over the south Indian Ocean (Fig. 1a, solid line) is larger than 0.8 in 2000 and 2001 and decreases to about 0.1 from 2001 to 2005. The error remains small after 2005, which indicates a good maintenance of the observational array. The number of $T / S$ profiles within the decorrelation scale around each grid increases from 2001 to 2007 and is about 200 or larger after 2007 (Fig. 1a, dashed line). There was a region with sparse observations in 2003 in the middle of the south Indian Ocean $\left(10^{\circ}-30^{\circ} \mathrm{S}, 75^{\circ}-\right.$ $90^{\circ} \mathrm{E}$; Fig. 1b). This data gap was filled in 2010 , for example, when observations covered the whole basin (Fig. 1c). Note that errors were large south of $35^{\circ} \mathrm{S}$ in both years owing to the outcropping of this density surface. In this study, we focus on the period after 2004, for which our $T / S$ estimates are reliable. The end of our analysis period is 2015 , until which output of the ocean reanalysis is available (described below). To judge the significance of obtained anomalies, we computed dimensional error as standard deviation of $T$ and $S$ at each grid point multiplied by nondimensional error and plotted anomalies only when their magnitude exceeded dimensional error. Here, standard deviations were calculated in each year using 300 hydrographic observations closest to each grid point. Dimensional error is a measure for uncertainty owing to sparsity of observations and spatial and temporal variability of input data that is not resolved in our analysis.

In addition, we calculated mixed layer density from in situ $T / S$ observations. The definition of mixed layer depth (MLD) is the depth where potential density is higher than the $10-\mathrm{m}$ value by $0.03 \mathrm{~kg} \mathrm{~m}^{-3}$, following de Boyer Montégut et al. (2004). Potential density was averaged over the mixed layer, and the resulting mixed layer density was objectively mapped on the same $1^{\circ} \times 1^{\circ}$ grid for each calendar month with decorrelation scales of $6^{\circ}$ in longitude, $3^{\circ}$ in latitude, and 45 days in time. From this mapping, we obtained monthly climatologies of mixed layer density. When the seasonal maximum of climatological mixed layer density is larger than, for example, $25 \sigma_{\theta}$, we consider that the $25 \sigma_{\theta}$ surface outcrops there. 


\section{b. Ocean reanalysis}

The ocean reanalysis used in this study is the Ocean Reanalysis System 4 (ORAS4; Balmaseda et al. 2013), which uses the Nucleus for European Modeling of the Ocean (NEMO) ocean general circulation model (Madec 2008) and assimilates in situ observations obtained from Argo floats, CTDs, expendable bathythermograph, mooring buoys, and satellite altimetry observations. The assimilation was carried out using a kind of a three-dimensional variational method. The model was forced by surface fluxes obtained from the European Centre for Medium-Range Weather Forecasts (ECMWF) atmospheric reanalysis. The grid system of NEMO is a tripolar grid, and we used output interpolated onto a $1^{\circ} \times 1^{\circ}$ grid. Monthly averages of ORAS4 output are available up to the end of 2015. The time series from 2004 to 2015 was used, which is the same for the analysis period for in situ observations.

We interpolated ORAS4's $T / S$ output onto the same $\sigma_{\theta}$ levels as those for in situ hydrographic observations. We averaged the resulting isopycnal $T$ and $S$ over each calendar year for consistency with in situ observations. In addition, we calculated monthly climatological mixed layer density from ORAS4 output with the same definition of MLD as that for observations and used it to specify the outcrop region of isopycnals. Note that MLD for ORAS4 was calculated from monthly averages, which possibly leads to an underestimate of $10-20 \mathrm{~m}$ compared to MLD obtained from instantaneous profiles (Toyoda et al. 2017).

\section{c. Other datasets}

Absolute velocity on isopycnals on a $1^{\circ} \times 1^{\circ}$ grid was obtained from estimates of Nagura and McPhaden (2018). In this dataset, the mean absolute velocity was computed from geostrophic velocity shear obtained from in situ hydrographic observations and absolute velocity at $1000-\mathrm{m}$ depth estimated from Argo float trajectories. Meteorological data at the sea surface were obtained from the ERA-Interim (Dee et al. 2011). We used monthly averages on a $0.75^{\circ} \times 0.75^{\circ}$ grid for latent and sensible heat fluxes, net longwave and shortwave radiation, winds, and pressure at the sea surface. We obtained monthly averages of SST on a $1^{\circ} \times 1^{\circ}$ grid from the National Oceanic and Atmospheric Administration Optimum Interpolation SST V2 (NOAA OI SST; Reynolds et al. 2002). The analysis period of these datasets is from 2004 to 2015, which is the same as those for in situ observations and the ocean reanalysis.

We used the following datasets to discuss the sensitivity of our results to the choice of datasets. We obtained $T / S$

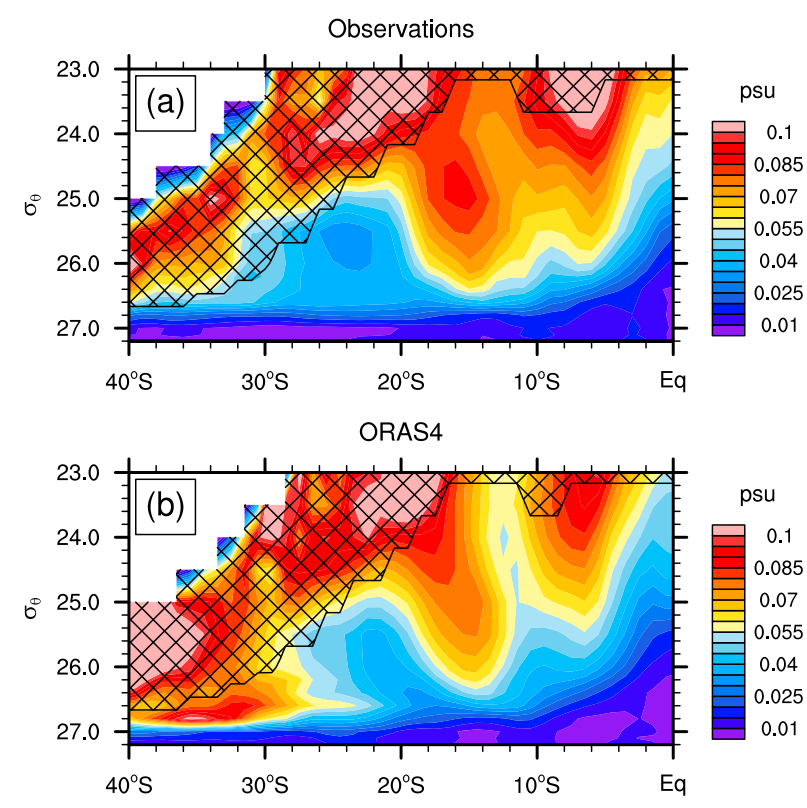

FIG. 2. Standard deviations of spiciness anomalies (psu) averaged over $50^{\circ}-110^{\circ} \mathrm{E}$ as a function of latitude and potential density: (a) observations and (b) ORAS4. Hatching indicates the region included by the wintertime mixed layer.

data from the Grid Point Value of the Monthly Objective Analysis using Argo float data (MOAA GPV; Hosoda et al. 2008), which objectively maps in situ $T / S$ observations obtained from Argo floats, moored buoys, and CTD casts on isobaric surfaces. Surface heat flux was obtained from TropFlux (Praveen Kumar et al. 2012), which was calculated using bulk formulas and surface meteorological data from ERA-Interim and satellite measurements. The surface meteorological data were corrected in comparison to in situ moored buoy observations before the calculation of fluxes. Evaporation rate was from $\mathrm{Ob}$ jectively Analyzed Air-Sea Fluxes (OAFlux; Yu and Weller 2007), which was constructed by blending various satellite retrievals and reanalysis data. Precipitation data were from the Global Precipitation Climatology Project (GPCP; Huffman et al. 1997; Adler et al. 2003), which is based on satellite and surface rain gauge observations. We used monthly averages for all these datasets. The analysis period is the same as that for other datasets, from 2004 to 2015 . Horizontal grid intervals are $1^{\circ} \times 1^{\circ}$ for MOAA GPV, TropFlux, and OAFlux and $2.5^{\circ} \times 2.5^{\circ}$ for GPCP.

\section{Spatial and temporal pattern}

In the interior north of $20^{\circ} \mathrm{S}$, the amplitude of spiciness anomalies has two meridional peaks, one at about $6^{\circ} \mathrm{S}$ and the other at $15^{\circ} \mathrm{S}$ (Fig. 2). Li and Wang (2015) attributed the former to interior advection but found no 
generation mechanism for the latter. Here we focus on the one at $15^{\circ} \mathrm{S}$, which is confined to the layers lighter than $26 \sigma_{\theta}$. According to Tsubouchi et al. (2010), mode waters generated in the southern Indian Ocean are heavier than $25.8 \sigma_{\theta}$, which indicates that spiciness anomalies at $15^{\circ} \mathrm{S}$ are distinguishable from $T / S$ variations in mode water in terms of density. Both observations and the reanalysis show these peaks with a similar magnitude. Spiciness anomalies are large in amplitude south of $26^{\circ} \mathrm{S}$ between 26 and $27 \sigma_{\theta}$ in the reanalysis, which is possibly related to $T / S$ variations in the Subantarctic Mode Water (SAMW) and the Antarctic Intermediate Water (AAIW) reported by Bindoff and McDougall (2000) and McDonagh et al. (2005). Observational results miss this feature for unknown reasons.

Temporal variability in temperature at a fixed pressure can be decomposed into contributions from spiciness variation and thermocline heave (e.g., Arbic and Owens 2001):

$$
\left.\frac{d \theta}{d t}\right|_{p}=\left.\frac{d \theta}{d t}\right|_{n}-\left.\frac{d p}{d t}\right|_{n} \frac{\partial \theta}{\partial p},
$$

where $\theta$ and $p$ denote potential temperature and pressure, respectively. The subscripts $p$ and $n$ denote that the derivative is along the constant pressure and the neutral surface, respectively (here the neutral surface is defined as isopycnals). The derivation assumes that vertical gradients of temperature $(\partial \theta / \partial p)$ are constant in time. The first term on the right-hand side (rhs) represents temperature variability owing to spiciness variations and is referred to as the spiciness term here. The second term of the rhs is that due to thermocline heave and referred to as the heave term. We calculated $d \theta /\left.d t\right|_{n}\left(d p /\left.d t\right|_{n}\right)$ as year-to-year changes in isopycnal temperature (pressure) and estimated its magnitude as the standard deviation. We calculated $\partial \theta / \partial p$ from the long-term (2004-15) mean of temperature and isopycnal pressure.

The spiciness term is large in magnitude from $4^{\circ}$ to $20^{\circ} \mathrm{S}$ in the layers lighter than $26.5 \sigma_{\theta}$ and shows two peaks at about $6^{\circ}$ and $15^{\circ} \mathrm{S}$ (Figs. 3a,d), as the magnitude of spiciness anomalies does (Fig. 2). The heave term is large north of $14^{\circ} \mathrm{S}$ in the layers lighter than $25.5 \sigma_{\theta}$ (Figs. 3b,e). The ratio of the spiciness to the heave term is smaller than unity for all latitudes and isopycnals (Figs. 3c,f), which shows that thermocline heave contributes more to isobaric temperature variability than spiciness anomalies. The contribution from spiciness anomalies is relatively large between $12^{\circ}$ and $20^{\circ} \mathrm{S}$ and between 24.5 and $26.5 \sigma_{\theta}$, where the ratio is about 0.6 at maximum. This shows that spiciness anomalies at $15^{\circ} \mathrm{S}$ have a larger contribution to isobaric temperature variability than those at $6^{\circ} \mathrm{S}$. Results from ORAS4 compare well with those in observations, although the reanalysis underestimates the magnitude of the spiciness and heave terms (Figs. 3d,e) and overestimates their ratio (Fig. 3f). The reanalysis shows a large magnitude of the spiciness term between 26 and $27 \sigma_{\theta}$ south of $26^{\circ} \mathrm{S}$ (Fig. 3d), which may be related to variations in SAMW and AAIW (Bindoff and McDougall 2000; McDonagh et al. 2005).

$\mathrm{Li}$ and Wang (2015) only presented longitude-time diagrams to examine spreading of spiciness anomalies. Here, we show the horizontal maps to discuss where anomalies come from (Figs. 4 and 5). The patterns of spiciness anomalies are compared with particle trajectories, which are advected by the mean currents shown in Fig. 6 (contours and vectors). Nine particles were deployed in 2005 to track positive anomalies and another nine in 2012 for negative anomalies. Note that observational mean velocity estimates (contours in Fig. 6a) were mapped using a decorrelation scale of $6^{\circ}$ in longitude and do not fully resolve western boundary currents, and particles advected by this velocity dataset do not move when they hit the western boundary.

Positive spiciness anomalies ( $>0.1 \mathrm{psu})$ spread to the west between $15^{\circ}$ and $20^{\circ} \mathrm{S}$ from 2005 to 2008 , which is roughly consistent with the westward movement of the particles (Figs. 4b-e and 5b-e). In 2007 and 2008, a tilted band of positive anomalies is formed from about $15^{\circ} \mathrm{S}$, $50^{\circ} \mathrm{E}$ to $20^{\circ} \mathrm{S}, 110^{\circ} \mathrm{E}$. Particles initially located at lower latitudes spread faster to the west, being advected by the swift SEC. Those initially located at higher latitudes are first advected to the north by the subtropical gyre, flow into the SEC, and then move to the west. As a result, particles initially confined to a square box are stretched out and result in a zonally elongated pattern aligned from west-northwest to east-southeast. Negative anomalies $(<-0.1 \mathrm{psu})$ spread to the westnorthwest from 2012 to 2014 consistently with particle movements and form a pattern of a tilted band in 2014 (Figs. 4i-k and 5i-k). A discrepancy between spiciness anomalies and particle locations is found in reanalysis results in 2007 (Fig. 5d), where two particles (asterisk and plus symbols) move to the northwest farther than positive spiciness anomalies. Possible reasons for this are dissipation of spiciness anomalies near the western boundary and/or interannual variability in velocity.

Reanalysis results show the spreading of spiciness anomalies to the equatorial region along the east coast of the African continent, which is consistent with particle movements (Figs. 5e,f,k). The equatorward intrusion along the eastern African coast is less clear but still discernible in observations (Figs. 4e,k). This suggests a 
Observations

(a) $d \theta /\left.d t\right|_{n}$

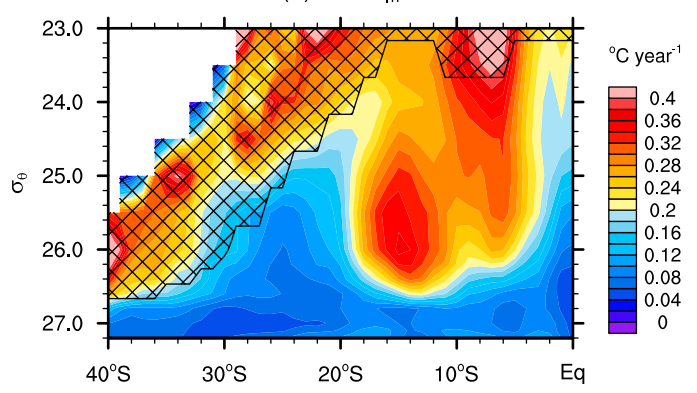

(b) $-d p /\left.d t\right|_{n} \partial \theta / \partial p$

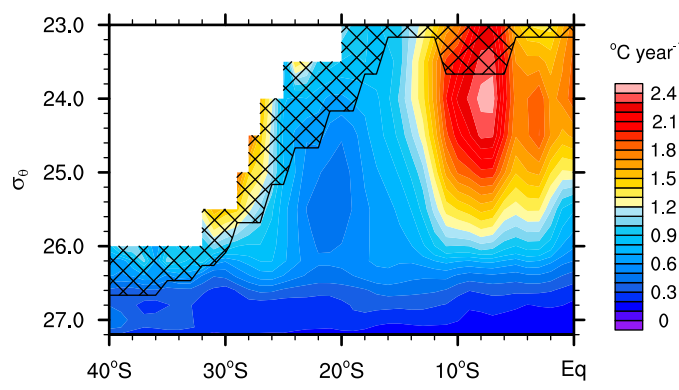

(c) Ratio

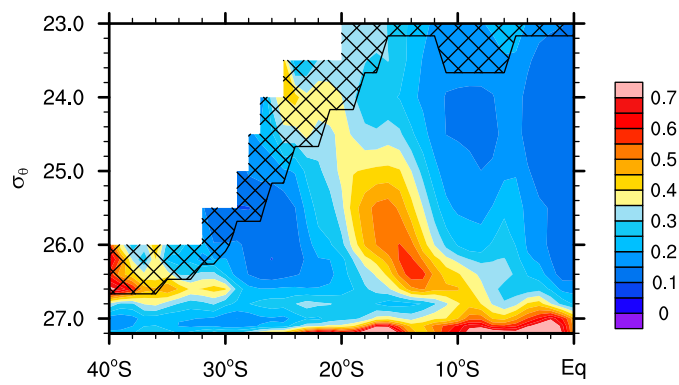

ORAS4

(d) $d \theta /\left.d t\right|_{n}$

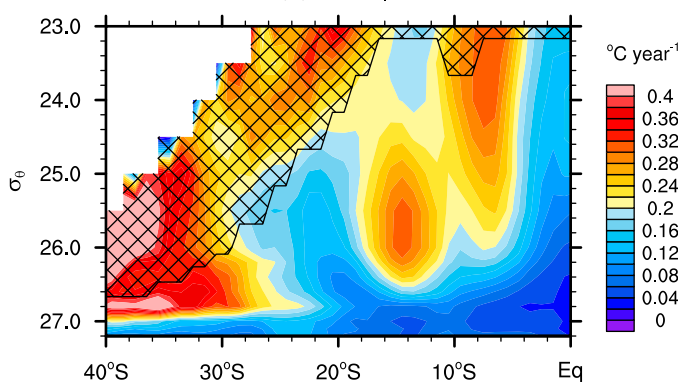

(e) $-d p /\left.d t\right|_{n} \partial \theta / \partial p$

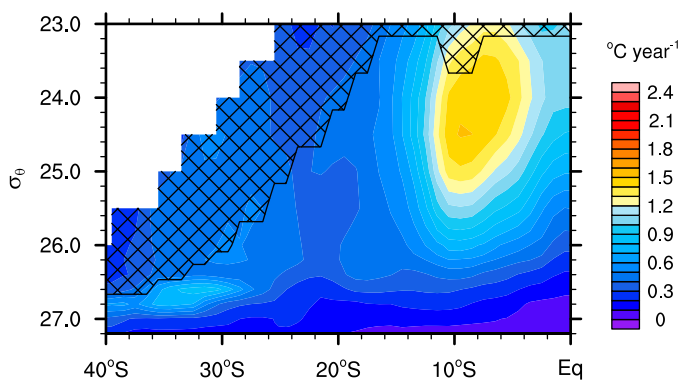

(f) Ratio

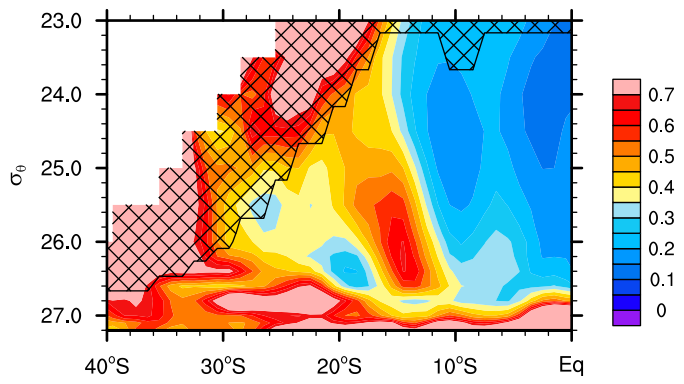

FIG. 3. Contributions from (a),(d) spiciness anomalies and (b),(e) thermocline heave to isobaric temperature variability as a function of potential density and latitude. The contributions from spiciness anomalies and thermocline heave were calculated as standard deviations of the first and second terms on the rhs of Eq. (1), respectively, and averaged over $50^{\circ}-110^{\circ} \mathrm{E}$ (see text for details). Note that different color scales are used for the top and middle panels. (bottom) The ratio of the contributions from spiciness anomalies to those from thermocline heave for (c) observational results and (f) ORAS4. Hatching indicates the region included by the wintertime mixed layer.

possible influence of spiciness anomalies on $T / S$ variability in low latitudes.

\section{Generation}

\section{a. Generation region}

As is mentioned in the introduction, spiciness anomalies along $15^{\circ} \mathrm{S}$ of the Indian Ocean cannot be explained by advection due to interior flow ( $\mathrm{Li}$ and Wang 2015). We can hypothesize that spiciness anomalies are generated in a boundary region, where diapycnal input of heat and/or freshwater alters the $T / S$ relationship of seawater. A plausible generation region is the outcrop region of the $25 \sigma_{\theta}$ surface in the southeastern Indian Ocean $\left(25^{\circ} \mathrm{S}, 85^{\circ}-110^{\circ} \mathrm{E}\right)$. The amplitude of anomalies is large from $15^{\circ} \mathrm{S}, 60^{\circ} \mathrm{E}$ to the outcrop region along the direction parallel to the subtropical gyre (Fig. 6). Anomalies spread from the outcrop region to the interior being advected by mean currents (Figs. 4 and 5). The Indonesian Throughflow (ITF) also feeds the SEC, but spiciness anomalies are small in amplitude in its upstream region $\left(10^{\circ}-15^{\circ} \mathrm{S}, 100^{\circ}-120^{\circ} \mathrm{E}\right.$; Fig. 6). 

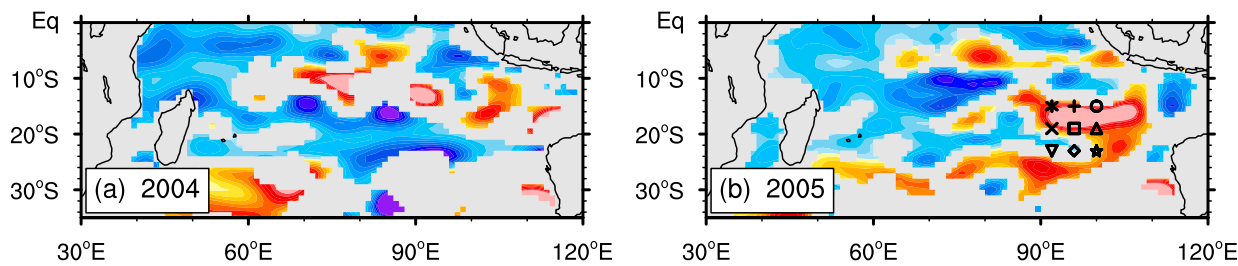

psu
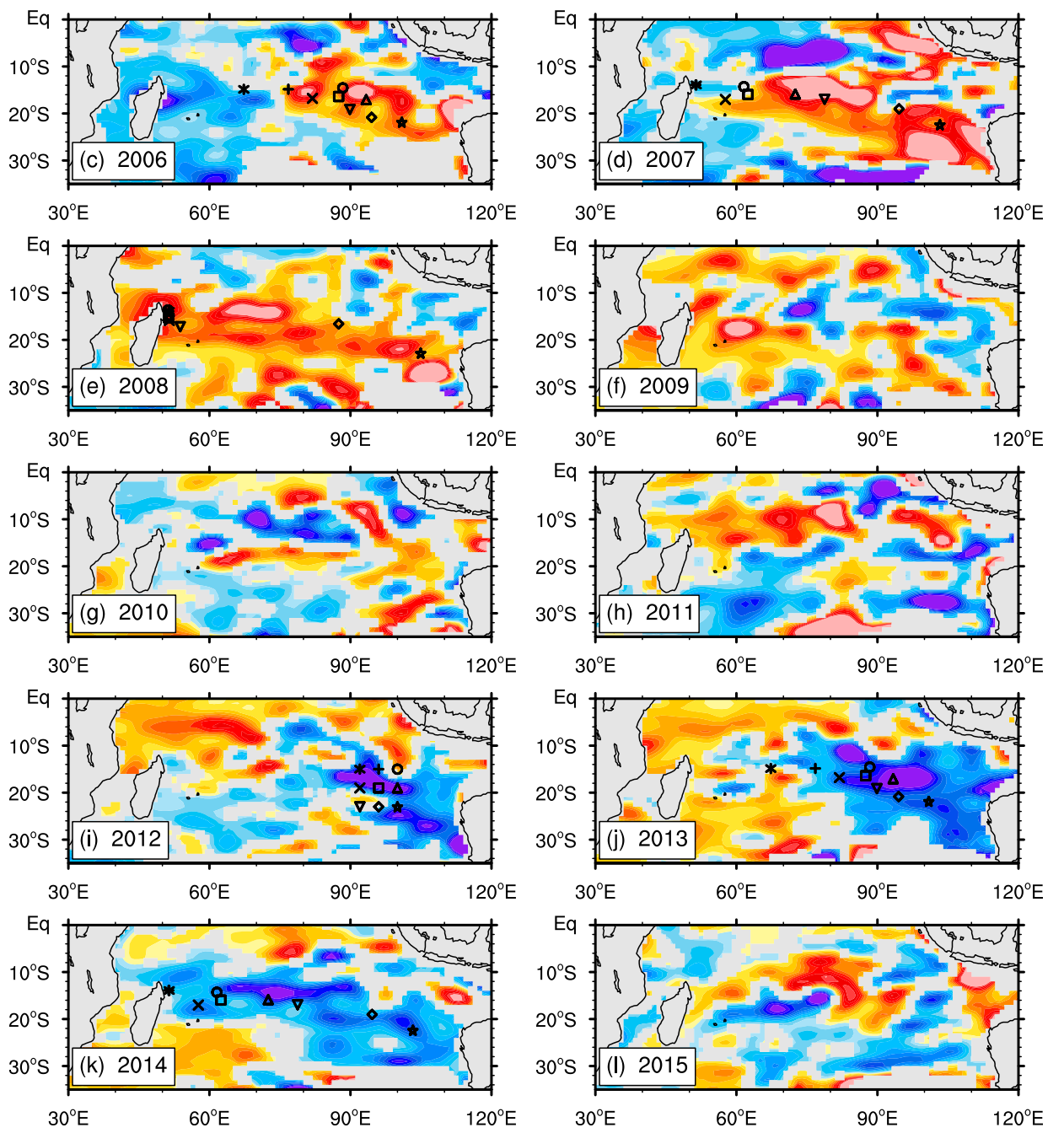

FIG. 4. Yearly estimates of spiciness anomalies obtained from observations. Anomalies were masked if they are smaller than error in magnitude. Symbols illustrate positions of nine artificial particles, which are deployed in 2005 and 2012 in the region from $15^{\circ}$ to $23^{\circ} \mathrm{S}$ and from $92^{\circ}$ to $100^{\circ} \mathrm{E}$ and advected by the mean observational velocity on $25 \sigma_{\theta}$ obtained from Nagura and McPhaden (2018).

Another source of the SEC is the Leeuwin Undercurrent (LUC; Smith et al. 1991; Domingues et al. 2007), which flows out of the northwest coast of Australia. The amplitude of spiciness anomalies is large in observations (Fig. 6a) but small in the reanalysis (Fig. 6b) in the upstream region of the LUC $\left(15^{\circ}-20^{\circ} \mathrm{S}, 110^{\circ}-120^{\circ} \mathrm{E}\right)$, suggesting unreliability of spiciness anomaly estimates there. Considering this, we assume that spiciness anomalies are generated in the outcrop region in the southeastern Indian Ocean.
Water mass generated in the surface mixed layer is released to the interior in spring, when the mixed layer thins. As a result, the property of interior water tends to reflect that of surface water in winter (Stommel 1979). At $25^{\circ} \mathrm{S}, 85^{\circ}-110^{\circ} \mathrm{E}$, the mixed layer is thickest in July (Fig. 7a). In this month, the mixed layer is thicker than $100 \mathrm{~m}$ south of $30^{\circ} \mathrm{S}$ and along the coast of Australia (Fig. 7b). The spatial variation in MLD is relatively small near the outcrop line of the $25 \sigma_{\theta}$ surface in the 

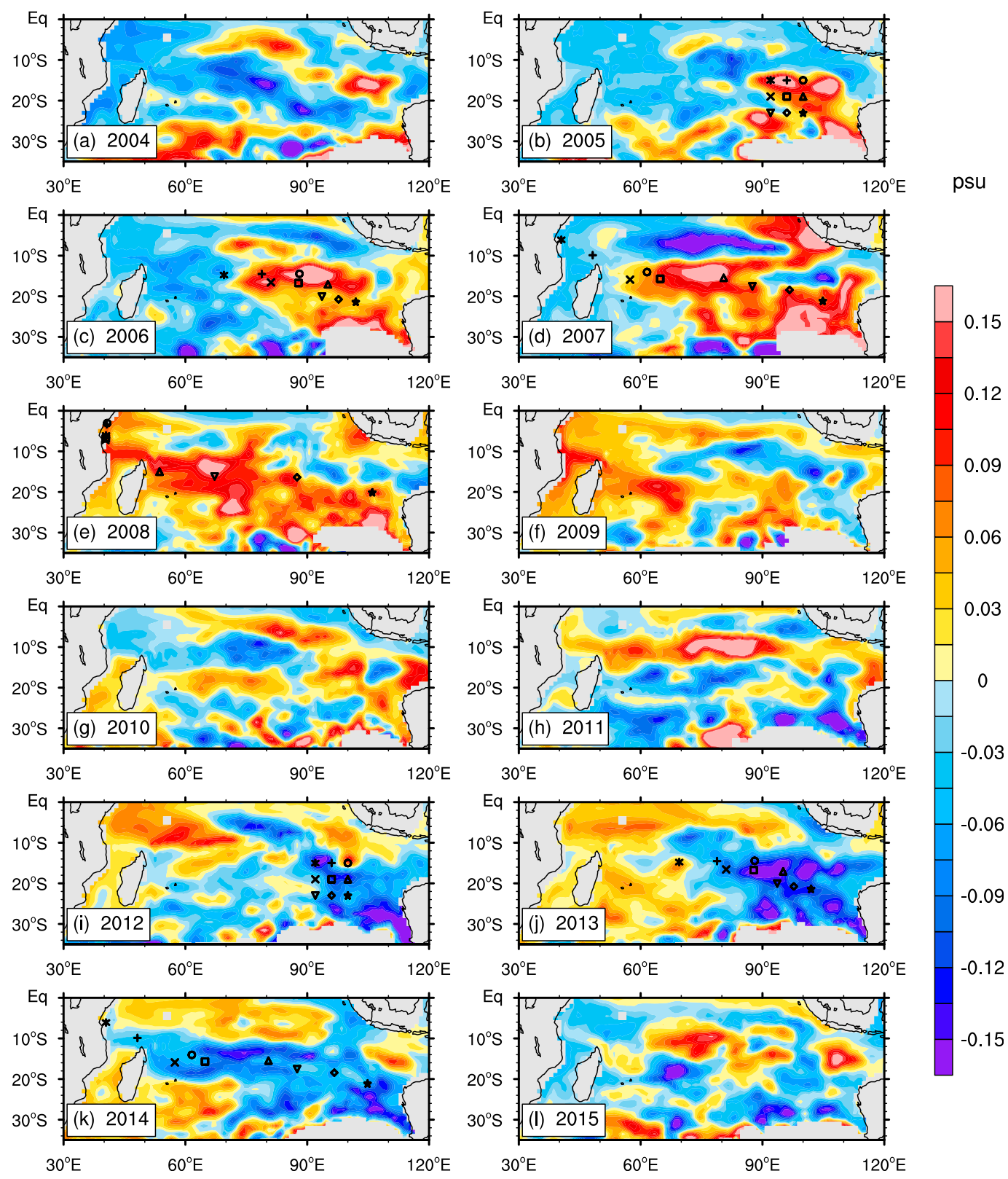

FIG. 5. As in Fig. 4, but for ORAS4. Artificial particles are advected by the mean absolute velocity from the reanalysis on $25 \sigma_{\theta}$.

interior. Surface winds are anticyclonic in relation to the Mascarene high, and Ekman pumping is downward most of the regions (Fig. 7c).

The annual subduction rate was calculated following Woods (1985) as $-w_{H}+v_{H} \partial_{y} H$, where $v_{H}$ and $w_{H}$ are meridional and vertical velocity at the base of the wintertime mixed layer, respectively, and $H=H(x, y)$ is the depth of the wintertime mixed layer base. The term $w_{H}$ was calculated as Ekman pumping velocity corrected by geostrophic shear in the mixed layer using the Sverdrup relationship (Williams 1991; Marshall et al. 1993): $w_{H}=\operatorname{curl}\left[\boldsymbol{\tau} /\left(\rho_{0} f\right)\right]-(\beta / f) \int_{-H}^{0} v d z$, where $\boldsymbol{\tau}$ is the surface wind stress vector, $\rho_{0}=1025 \mathrm{~kg} \mathrm{~m}^{-3}$ is the mean seawater density, $f$ is the Coriolis parameter, and $\beta$ is the meridional gradient of $f$. We obtained surface wind stress from ERA-Interim and meridional velocity and wintertime MLD from ORAS4. Here we considered lateral input only in the meridional direction. The annual subduction rate amounts to about a few hundred meters per year south of $30^{\circ} \mathrm{S}$ (Fig. $7 \mathrm{~d}$ ), where mode 

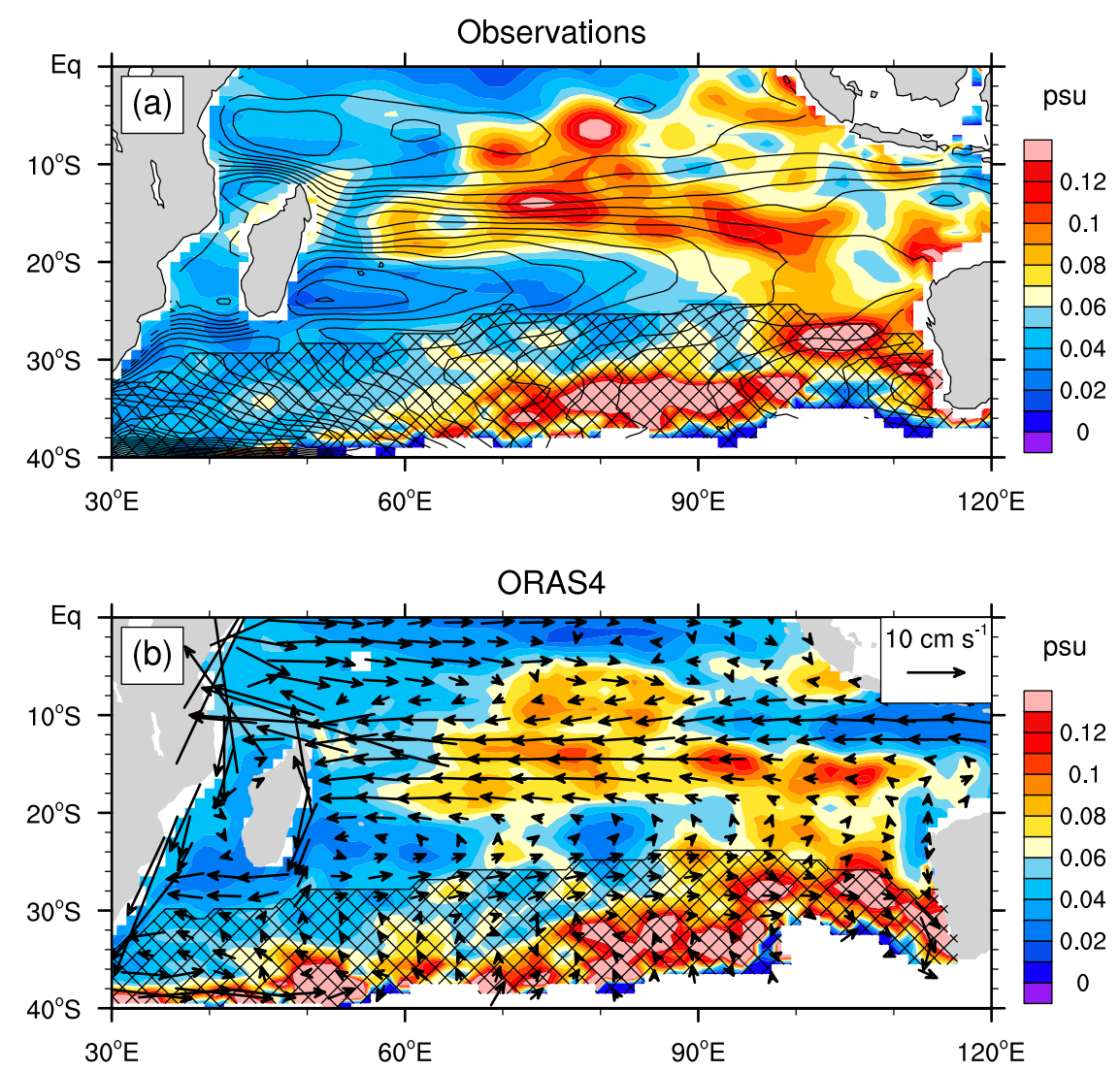

FIG. 6. Standard deviations of spiciness anomalies (colors), streamlines [contours in (a)], and velocity vectors [arrows in (b)] for the mean current on $25 \sigma_{\theta}$ for (a) observations and (b) ORAS4. Hatching indicates the region included by the wintertime mixed layer.

water is formed (Karstensen and Quadfasel 2002; Tsubouchi et al. 2010; Liu and Huang 2012). The outcrop line of the $25 \sigma_{\theta}$ surface is located at about $25^{\circ} \mathrm{S}$, which is north of the formation region of mode water. This is consistent with results in Fig. 2, in which spiciness anomalies at $15^{\circ} \mathrm{S}$ are lighter than mode water. The subduction rate at the $25 \sigma_{\theta}$ outcrop line is about $50 \mathrm{~m} \mathrm{yr}^{-1}$, most of which is owing to downwelling at the base of the mixed layer rather than lateral induction, as is expected from small spatial gradient in MLD (Fig. 7b) and relatively weak horizontal currents (Fig. 6). Vertical pumping $\left(-w_{H}\right)$ and lateral induction $\left(v_{H} \partial_{y} H\right)$ averaged over the region near the $25 \sigma_{\theta}$ outcrop line $\left(23^{\circ}-27^{\circ} \mathrm{S}, 85^{\circ}-110^{\circ} \mathrm{E}\right)$ are about 49 and $4 \mathrm{~m} \mathrm{yr}^{-1}$, respectively.

Near the $25 \sigma_{\theta}$ outcrop line, SST increases and sea surface salinity (SSS) decreases to the north in winter (Figs. 7e,f). Fresh surface water at lower latitudes is a result of precipitation and outflow from the ITF, and saline surface water at about $30^{\circ} \mathrm{S}$ is related to evaporation under trade winds. These results illustrate that $25 \sigma_{\theta}$ water is produced at the region under the warm-fresh and cool-saline $T / S$ relationship, which does not tend to be density compensating. This $T / S$ relationship is crucial in the generation mechanism of spiciness anomalies, as is discussed in the next subsection.

In the next subsection we base our analysis on ORAS4. To examine the generation of spiciness anomalies, we need to focus on the surface $T / S$ relationship in winter, but our hydrographic analysis is for yearly averages and does not resolve seasonal variability. Also, our hydrographic analysis is estimated on isopycnal surfaces, which is not suitable to examine processes in the surface mixed layer. Good comparisons between in situ observations and reanalysis results presented so far validate the use of the reanalysis. For cross checking, we use a different set of observational datasets and corroborate results.

\section{b. Generation mechanism}

As is discussed in the introduction, previously proposed mechanisms of spiciness anomaly generation were based on density-compensating $T$ and $S$ in the generation region. This is not the case in the current 
(a)

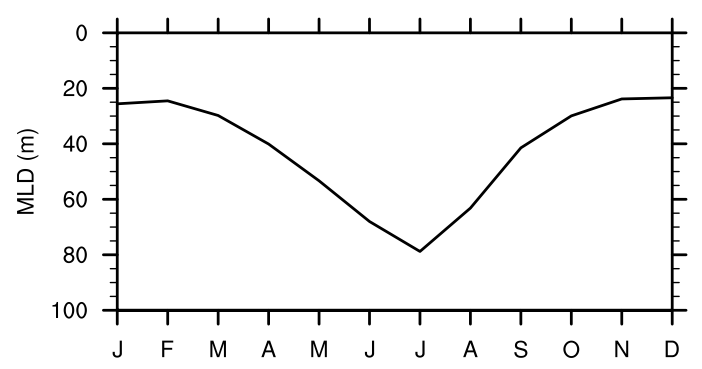

(c)

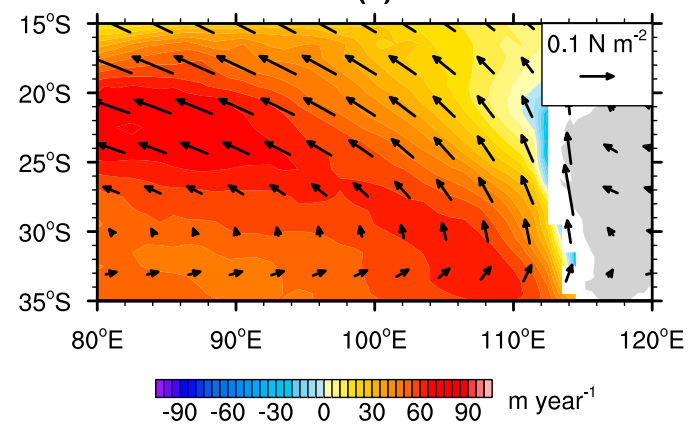

(e)

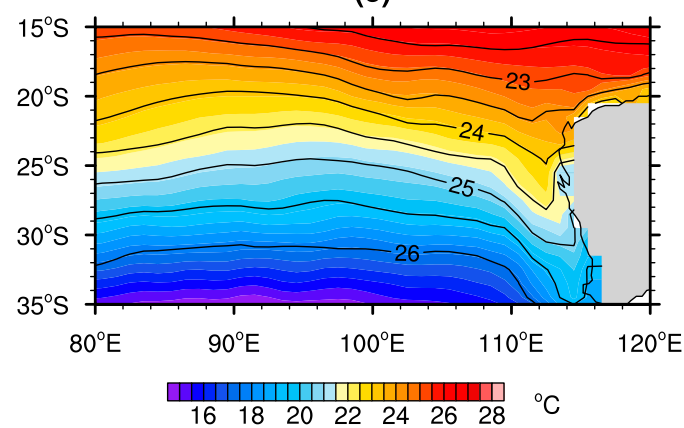

(b)

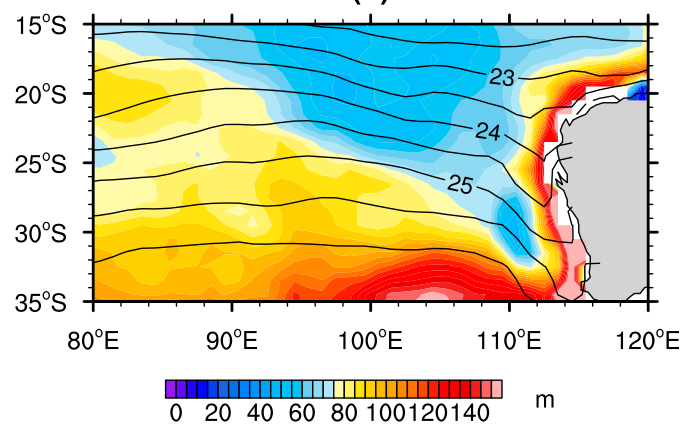

(d)

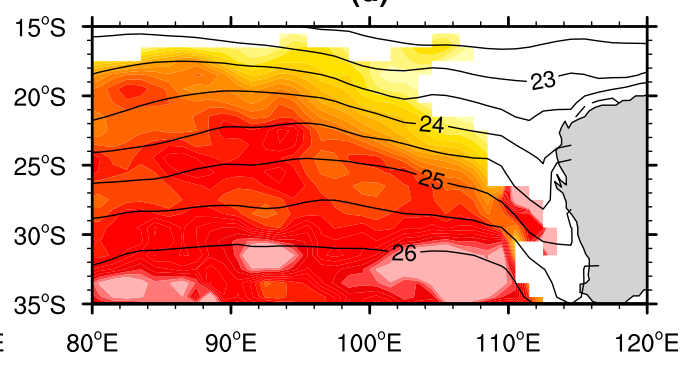

\begin{tabular}{lllll|l|l|l|}
-90 & -60 & -30 & 0 & 30 & 60 & 90 & m year $^{-1}$
\end{tabular}

(f)

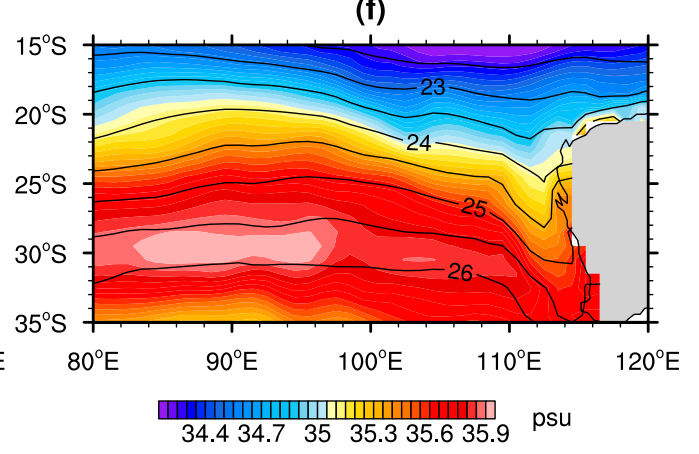

FIG. 7. Climatological surface conditions of the south Indian Ocean. (a) Monthly MLD in $25^{\circ} \mathrm{S}, 85^{\circ}-110^{\circ} \mathrm{E}$, (b) MLD in July, (c) annual-mean Ekman pumping velocity (positive means downward), (d) annual subduction rate, (e) SST in July, and (f) sea surface salinity in July. Contour lines in (b) and (d)-(f) are for surface potential density in July. Arrows in (c) are for the annual-mean surface wind stress. Negative subduction rate has been masked out. Results were obtained from ORAS4 and ERA-Interim.

case (Figs. 7e,f and 8a). In addition, salinity shows a subsurface peak related to the saline South Indian Subtropical Water (Wijffels et al. 2002) near the $25 \sigma_{\theta}$ outcrop line, and both $T$ and $S$ stabilize the surface stratification. Thus, $T$ and $S$ near the surface are not density compensating in the meridional or vertical direction. Previously proposed mechanisms are inapplicable to our case.

Katsura et al. (2013) examined the mixed layer salinity budget in the North Pacific Ocean and discussed the generation mechanism of spiciness anomalies. Schneider et al. (1999) conducted the analysis of the mixed layer temperature budget in the North Pacific Ocean for a similar purpose. We are skeptical if a mixed layer budget analysis in a fixed domain is useful in the current case. The time series of zonally averaged SST, SSS, and surface density show the meridional movement of isopleths for SST and SSS in tandem with those for surface density (Figs. 8b,c), which is probably caused by meridional advection. Pure advection does not generate a spiciness anomaly if SST and SSS are not density compensating, because advection does not alter the $T / S$ relationship on a density surface. It is expected that the budget analysis of mixed layer $T$ or $S$ is 


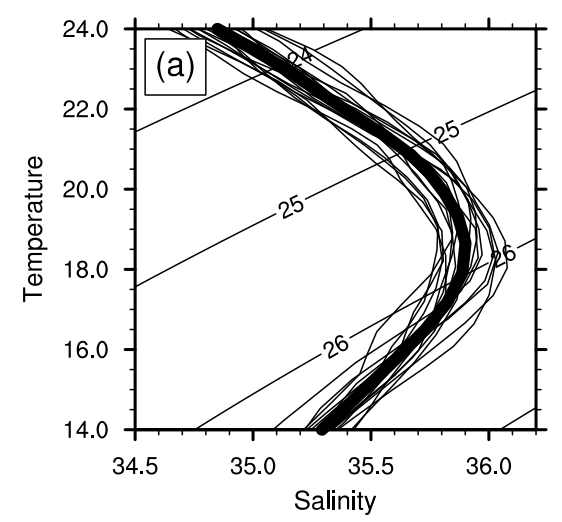

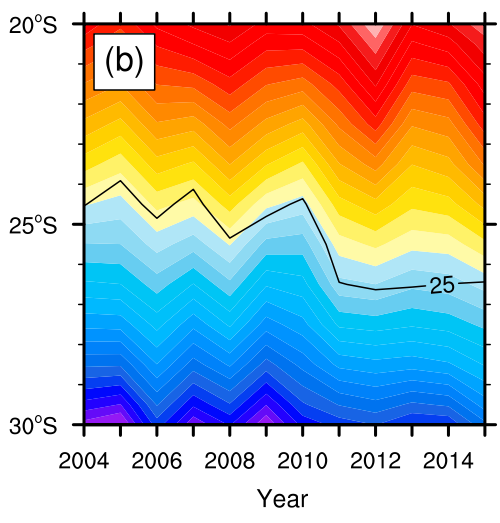

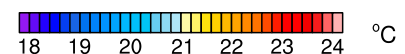

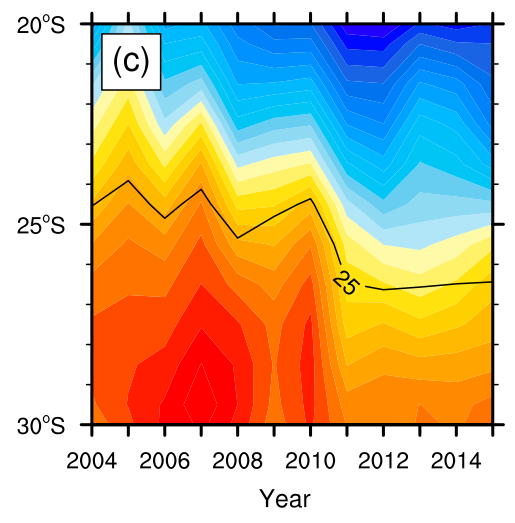

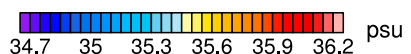

FIG. 8. SST and SSS in July averaged over $85^{\circ}-110^{\circ} \mathrm{E}$ obtained from ORAS4. (a) The $T / S$ relationship for each year (thin curves) and climatological mean (thick curve), and time series for (b) SST and (c) SSS. Overlaid in (a) are the lines of constant density for 24-27 $\sigma_{\theta}$. Solid lines in (b) and (c) illustrate the latitude where $\sigma_{\theta}=25$.

dominated by the effect of advection in our case, which is irrelevant to the production of spiciness variations. This problem did not arise in Katsura et al. because they confined the analysis domain to the narrow region near salinity maximum, where horizontal advection is negligible.

Our analysis is based on the examination of the $T / S$ diagram. In Fig. 9, the line of constant density is shown by the thin solid line whose inclination is $\alpha_{S} / \alpha_{T}$, where $\alpha_{T}$ and $\alpha_{S}$ are the thermal expansion coefficient and the saline contraction coefficient of seawater, respectively. The thick line illustrates the $T / S$ relationship of the surface water. Both the line of the constant density and that of SST/SSS relationship are approximated by a straight line. If a water particle is warmed by $\Delta \theta$ without any change in salinity, newly generated water joins the density surface of our interest (Fig. 9a, filled squares), which brings a higher $S$ and $T$ (cf. the filled circle and filled square). The resulting variation in isopycnal $T$ $\left(\left.\theta^{\prime}\right|_{n}\right)$ and $S\left(\left.S^{\prime}\right|_{n}\right)$ is related to $\Delta \theta$ as

$$
\Delta \theta=\left.\theta^{\prime}\right|_{n}-\left.\frac{\partial \theta}{\partial S} S^{\prime}\right|_{n}=\left.\left(\frac{\alpha_{S}}{\alpha_{T}}-\frac{\partial \theta}{\partial S}\right) S^{\prime}\right|_{n}
$$

where $\partial \theta / \partial S$ denotes the inclination of the SST/SSS line and is negative here (see Fig. 8a near $25 \sigma_{\theta}$ ); (a) Pure Warming

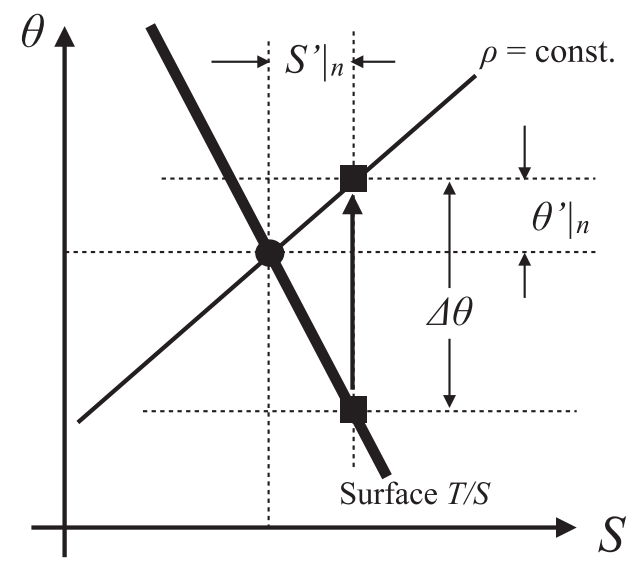

(b) Pure Salinification

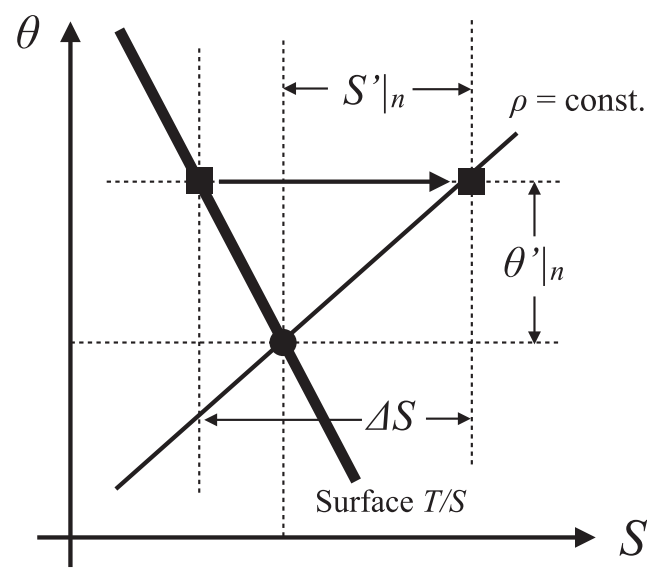

FIG. 9. Schematic illustration of the generation of spiciness anomaly due to (a) pure warming and (b) pure salinification. The thin solid line shows the line of constant density. The thick solid line is for the $T / S$ relationship of the surface water. Newly generated water (filled square) has a different $T / S$ characteristic from the original water particle (filled circle). 
$\left.\alpha_{T} \theta^{\prime}\right|_{n}=\left.\alpha_{S} S^{\prime}\right|_{n}$ by definition. The spiciness anomaly generated by pure warming $\Delta \theta$ is written as

$$
\left.S^{\prime}\right|_{n}=\left(\frac{\alpha_{S}}{\alpha_{T}}-\frac{\partial \theta}{\partial S}\right)^{-1} \Delta \theta .
$$

Here $\Delta \theta$ is considered to be a Lagrangian change of mixed layer temperature. If atmospheric forcing dominates the surface Lagrangian heat budget, $\Delta \theta$ can be computed as

$$
\Delta \theta=\int \frac{Q}{\rho_{0} c_{p} h} d t,
$$

where $Q$ is the surface heat flux to the ocean, $c_{p}$ is the specific heat of seawater, and $h$ is MLD. We have neglected the effects of entrainment/detrainment and diffusion. Collectively, newly formed water has a spiciness anomaly which is written as

$$
\left.S^{\prime}\right|_{n}=\left.\frac{1}{\rho_{o} c_{p}}\left(\frac{\alpha_{S}}{\alpha_{T}}-\frac{\partial \theta}{\partial S}\right)^{-1} \int \frac{Q}{h} d t \equiv S^{\prime}\right|_{n} ^{w} .
$$

Below we refer to this value as $\left.S^{\prime}\right|_{n} ^{w}$.

If the salinity of a water particle increases without any change in temperature, the Lagrangian increase in salinity $\Delta S$ is related to the spiciness anomaly as (Fig. 9b)

$$
\Delta S=\left.S^{\prime}\right|_{n}-\left.\left(\frac{\partial \theta}{\partial S}\right)^{-1} \theta^{\prime}\right|_{n}=\left.\left[1-\left(\frac{\partial \theta}{\partial S}\right)^{-1} \frac{\alpha_{S}}{\alpha_{T}}\right] S^{\prime}\right|_{n} .
$$

If it is assumed that $\Delta S$ is caused by surface evaporation $E$ and precipitation $P,\left.S^{\prime}\right|_{n}$ can be related to $E-P$ as

$$
\left.S^{\prime}\right|_{n}=\left.\left[1-\left(\frac{\partial \theta}{\partial S}\right)^{-1} \frac{\alpha_{S}}{\alpha_{T}}\right]^{-1} \int \frac{S_{0}(E-P)}{h} d t \equiv S^{\prime}\right|_{n} ^{s},
$$

where $S_{0}$ is the typical surface salinity, and $\left.S^{\prime}\right|_{n} ^{s}$ refers to the resulting isopycnal $S$ anomaly.

Equations (5) and (7) were calculated from surface flux data as follows. In the region where the $25 \sigma_{\theta}$ surface outcrops $\left(23^{\circ}-27^{\circ} \mathrm{S}, 85^{\circ}-110^{\circ} \mathrm{E}\right)$, the area-averaged MLD in July is about $76 \mathrm{~m}$, and the area-averaged annual subduction rate is about $55 \mathrm{~m} \mathrm{yr}^{-1}$. This indicates that about $73 \%$ of the ventilated water is flushed away into the interior in each year. Here we assume that water in the wintertime mixed layer is totally refreshed each year, and the time integrals in Eqs. (5) and (7) were calculated from August to July in each year. This calculation ignores the effect of SST/SSS recurrence (Namias and Born 1970, 1974; Alexander and Deser 1995).

The time integrals of surface forcing in Eqs. (5) and (7) should be calculated following the trajectory of surface water. Here, for convenience, we calculated the integrals using area averages of $Q$ and $E-P$. A plausible trajectory of water particles is as follows. First, southeasterly winds north of $30^{\circ} \mathrm{S}$ (Fig. 7c) force southward Ekman currents. Water particles are advected to the south in the surface mixed layer, when they are exposed to atmospheric forcing and acquire spiciness anomalies. Eventually they subduct (Fig. 7d) and are advected equatorward by geostrophic currents (Figs. 4 and 5), bringing spiciness anomalies to the interior. The region for averaging $Q$ and $E-P$ was determined based on this scenario. The typical magnitude of Ekman currents is about $4 \mathrm{~cm} \mathrm{~s}^{-1}$, which advects water particles by about $10^{\circ}$ in a year, and thus our box is $10^{\circ}$ wide in the meridional direction. Since surface water is advected to the south, the box is located north of the $25 \sigma_{\theta}$ outcrop. We set a box in $15^{\circ}-27.5^{\circ} \mathrm{S}, 80^{\circ}-115^{\circ} \mathrm{E}$, which is referred to as the southeastern Indian Ocean (SEIO) box below. (We used a meridional width slightly larger than $10^{\circ}$, considering a possible contribution from horizontal diffusion.) Results were essentially the same if a slightly different region was used.

The term $h$ in Eqs. (5) and (7) denotes instantaneous MLD. Here, we replaced $h$ with a constant value, which is the seasonal maximum of area-averaged MLD ( $\sim 80 \mathrm{~m}$; Fig. 7a). This follows the concept of effective MLD proposed by Deser et al. (2003). Heat (or freshwater) input in summer gives rise to a rapid change in mixed layer temperature (salinity), because the mixed layer is thin in this season. However, the given heat or freshwater is eventually redistributed to the thick mixed layer in fall, and we only need to take wintertime MLD into account, if we focus on changes in $T$ and $S$ from one winter to another. We confirmed the correctness of this concept by experiments with a onedimensional mixed layer model (see the appendix). We ignored the entrainment/detrainment term from the $T$ and $S$ budget because of the use of a constant MLD. (We also neglected the thermal effect of advection across the base of the mixed layer.) Here the effective MLD is $80 \mathrm{~m}$, and we do not need to consider penetration of shortwave radiation across the base of the mixed layer.

We calculated $\partial \theta / \partial S$ from ORAS4. Climatological SST and SSS in July are averaged over $85^{\circ}-110^{\circ} \mathrm{E}$, and its meridional gradient at $25 \sigma_{\theta}$ is used as $\partial \theta / \partial S$. We used $c_{p}=3994 \mathrm{~J} \mathrm{~kg}^{-1} \mathrm{~K}^{-1}$ (for $T=20^{\circ} \mathrm{C}$ and $S=35 \mathrm{psu}$; Curry and Webster 1999) and $S_{0}=35.5$ psu.

For comparison, isopycnal $S$ anomalies at the outcrop line of the $25 \sigma_{\theta}$ surface were calculated from ORAS4 (Fig. 10a, solid line). The wintertime isopycnal $S$ anomaly at the outcrop line is larger than 0.05 psu from 2005 to 2008, small in magnitude in 2009 and 2010, and 

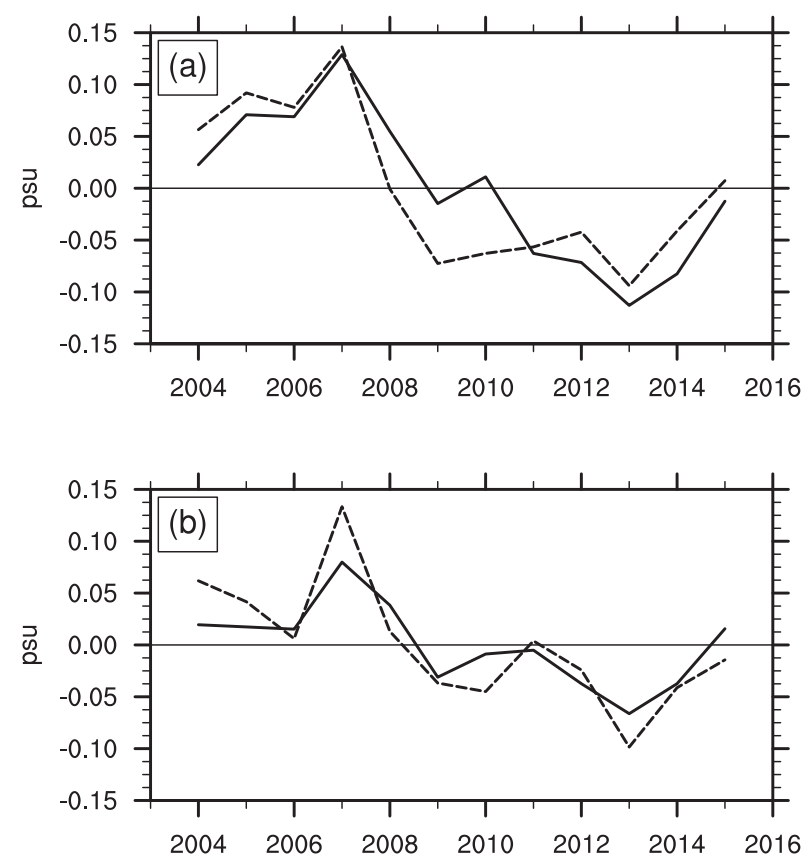

FIG. 10. Spiciness anomalies at the outcrop line of $25 \sigma_{\theta}$ calculated from $T / S$ data (solid line) and estimated from the surface heat and freshwater flux (dashed line). Spiciness anomalies were calculated from $T / S$ data as SSS anomalies in July at the line of constant density, $25 \sigma_{\theta}$, averaged over $85^{\circ}-110^{\circ} \mathrm{E}$. See text for the method of the estimation from surface fluxes. Note that the isopycnal $S$ anomaly in July 2010 is compared with the estimate derived from the integral of surface fluxes from August 2009 to July 2010 , for example. The sources of $T / S$ data are (a) ORAS4 and (b) MOAA GPV. Surface fluxes were obtained from ERA-Interim in (a) and TropFlux (heat flux), OAFlux (evaporation) and GPCP (precipitation) in (b). Anomalies were calculated as the deviation from the mean for the period from 2004 to 2015.

smaller than -0.05 psu from 2011 to 2014 . This temporal evolution roughly coincides with spiciness anomalies in the interior (Figs. 4 and 5). The magnitude of interior isopycnal $S$ anomalies is about 0.2 psu at most, and that of SSS anomalies at the outcrop line is about $0.1 \mathrm{psu}$, which shows consistency in amplitude (smaller amplitude for the latter is owing to zonal averaging).

The dashed line in Fig. 10a shows the sum of $\left.S^{\prime}\right|_{n} ^{w}$ and $\left.S^{\prime}\right|_{n} ^{s}$ computed from ERA-Interim surface fluxes. The estimate predicts the generation of positive spiciness anomalies before 2008 and that of negative anomalies from 2009 to 2014, which roughly agrees with isopycnal $S$ anomalies obtained from ORAS4 in terms of both polarity and amplitude. A discrepancy is found in 2009 and 2010, when the estimates from surface fluxes predict the generation of negative anomalies, whereas isopycnal SSS anomalies are almost zero. Apart from these two years, surface fluxes explain the overall tendency of spiciness anomaly production.
We repeated the calculation using a different set of datasets (Fig. 10b). Isopycnal $S$ anomalies obtained from MOAA GPV compare well with the estimates obtained from TropFlux, OAFlux, and GPCP, which supports the validity of our estimate. Positive (negative) spiciness anomalies are generated before 2008 (from 2009 to 2014), which is consistent with the results from ORAS4 and ERA-Interim. The estimates from fluxes and isopycnal $\mathrm{S}$ anomalies are in the same polarity and in a similar magnitude in 2009 and 2010 in Fig. 10b, which suggests that the discrepancy found in Fig. 10a in these years is dataset sensitive. Note that there are quantitative discrepancies between Figs. 10a and 10b. Isopycnal $S$ anomalies at the outcrop line calculated from MOAA GPV are half as small in magnitude as those from ORAS4. The estimates from TropFlux, OAFlux, and GPCP tend to be larger in magnitude than spiciness anomalies from MOAA GPV (e.g., in 2004, 2007, 2010, and 2013; Fig. 10b). Except for these quantitative details, our estimates based on surface fluxes compare well with isopycnal $S$ anomalies at the surface outcrop line.

Note that our method indicates that the efficacy of spiciness anomaly production depends on the surface $T / S$ relationship. The line for the surface $T / S$ relationship in Fig. 8a becomes vertical at about $25.8 \sigma_{\theta}$, which corresponds to the region with the salinity maximum (Fig. 7f). The value of $\partial \theta / \partial S$ is infinite there. For this condition, $\left.S^{\prime}\right|_{n} ^{w}$ is identical to zero [Eq. (5)], which indicates that surface heat flux cannot contribute to spiciness anomaly production. This may be consistent with results in Fig. 2, in which the amplitude of spiciness anomalies at $15^{\circ} \mathrm{S}$ decreases to the depth in the layers heavier than $25 \sigma_{\theta}$. For the layers heavier than $26 \sigma_{\theta}$, SST and SSS in the outcrop region tend to be density compensating (Fig. 8a), and the mechanisms proposed by past studies may be responsible for spiciness anomaly production.

\section{Relevance to climate modes}

In this section we discuss possible contributions from climate modes to the generation of spiciness anomalies. Figure 11a compares the contribution from surface heat flux $\left(\left.S^{\prime}\right|_{n} ^{w}\right.$; blue line) with that from freshwater flux $\left(\left.S^{\prime}\right|_{n} ^{s}\right.$; red line). The contribution from heat flux tends to be of the same sign as the sum, whereas that from freshwater flux tends to be of the opposite sign. Also, the amplitude of the heat flux contribution is larger than that of the freshwater flux contribution most of years. This result indicates that the surface heat flux is the main driver of spiciness anomaly generation.

Below we discuss the relationship of surface heat flux anomalies in the SEIO region with climate modes. 
(a) Spiciness anomalies

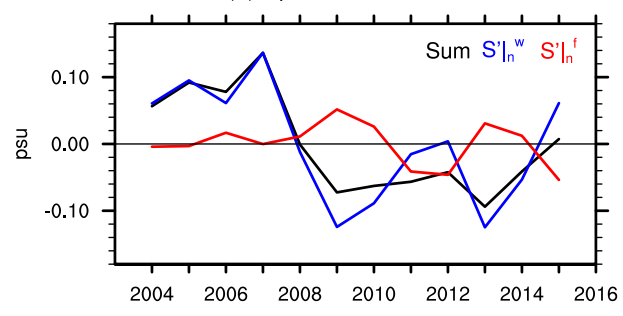

(c) Ningaloo Nino index

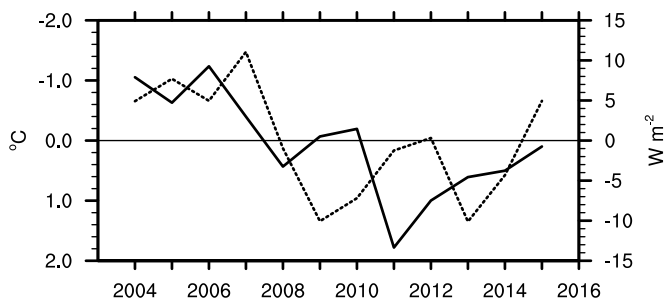

(b) Surface heat fluxes

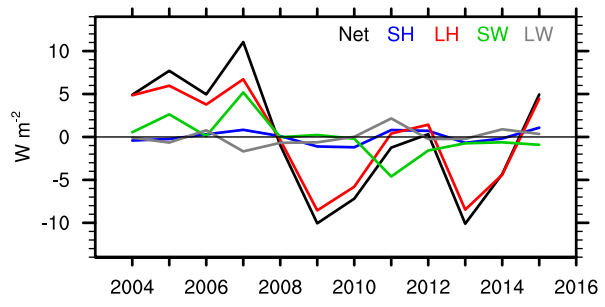

(d) Nino 3.4 index

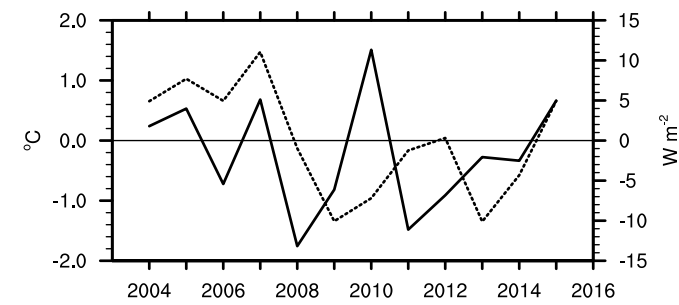

FIG. 11. (a) Spiciness anomalies estimated from surface heat flux $\left.S^{\prime}\right|_{n} ^{w}$ [blue; Eq. (5)], those estimated from surface freshwater flux $\left.S^{\prime}\right|_{n} ^{s}$ [red; Eq. (7)], and their sum (black). (b) Annual-mean surface heat flux anomalies averaged over the SEIO region $\left(15^{\circ}-27.5^{\circ} \mathrm{S}, 80^{\circ}-115^{\circ} \mathrm{E}\right)$ for net heat flux (black), sensible heat flux (blue), latent heat flux (red), shortwave radiation (green), and longwave radiation (gray). Annual means were calculated as the average over the period from August in a year to July in the next year. December-February means of (c) the Ningaloo Niño index (Kataoka et al. 2014) and (d) the Niño-3.4 index (Trenberth 1997). The DJF mean in 2010 is the average from December 2009 to February 2010, for example. Dotted lines in (c) and (d) are identical to the black line in (b). The vertical axis for heat flux is shown on the right in (c) and (d). The mean for the period from 2004 to 2015 was subtracted. Results were obtained from ERA-Interim and NOAA OI SST.

Considering the seasonality of climate modes, we averaged surface winds, sea level pressure (SLP) and SST over a season and regressed onto the net surface heat flux in the SEIO region averaged over the same season. Seasonal averages are calculated for austral spring (August-November), summer (December-March) and fall/winter (April-July), which correspond to the periods of detrainment, the thin mixed layer, and entrainment in the region of our interest (Fig. 7a). The annual-mean net surface heat flux anomalies in the SEIO region are compared with climate mode indices in Figs. 11c and 11d.

Positive net heat flux anomalies in the SEIO region tend to be related to reduced wind speeds for all the three seasons (Figs. 12a,d,g). This can be explained by the dominance of latent heat flux among the four components of surface heat fluxes (Fig. 11b) and the tendency of weaker (stronger) evaporation under weakened (strengthened) winds. Weakened wind speeds are accompanied by northwesterly anomalies in the SEIO region (Figs. 12a,d,g, vectors), which reduce the speed of the southeasterly trade winds (Fig. 7c). SLP anomalies are positive and negative north and south of the SEIO box, respectively (Figs. 12b,e,h), which is expected from geostrophy. SLP and SST anomalies are positive and negative, respectively, in summer off the west coast of Australia (Figs. 12e,f), which are known to be the typical pattern of the Ningaloo Niño (Feng et al. 2013; Kataoka et al. 2014). The index of the Ningaloo Niño tends to be positive in the former half of the analysis period and negative in the latter, showing some resemblance to the time evolution of the annual-mean net surface heat flux in the SEIO box (Fig. 11c). The correlation coefficient between these two indices for the period from 2004 to 2015 is just below the $85 \%$ confidence level $(r=-0.43)$, but that for a longer period (from 1983 to 2015) is above the $95 \%$ confidence level $(r=-0.38)$, indicating that the Ningaloo Niño is a possible contributor.

The positive SST anomalies in the equatorial Pacific in summer (Fig. 12f) indicate a contribution from ENSO. The correlation between Niño-3.4 index and net surface heat flux in the SEIO region is low $(r=0.23$; Fig. 11d), but if we exclude data in the exceptional year of 2010, it increases to 0.53 . The correlation between the two is significant at the $99 \%$ confidence level for the period from 1983 to $2015(r=0.52)$. Physically, it is plausible that ENSO causes wind variability in the tropical southeastern Indian Ocean via the impact on SLP over Indonesia (e.g., Wallace et al. 1998) and/or on the Ningaloo Niño (Feng et al. 2013; Kataoka et al. 2014). 

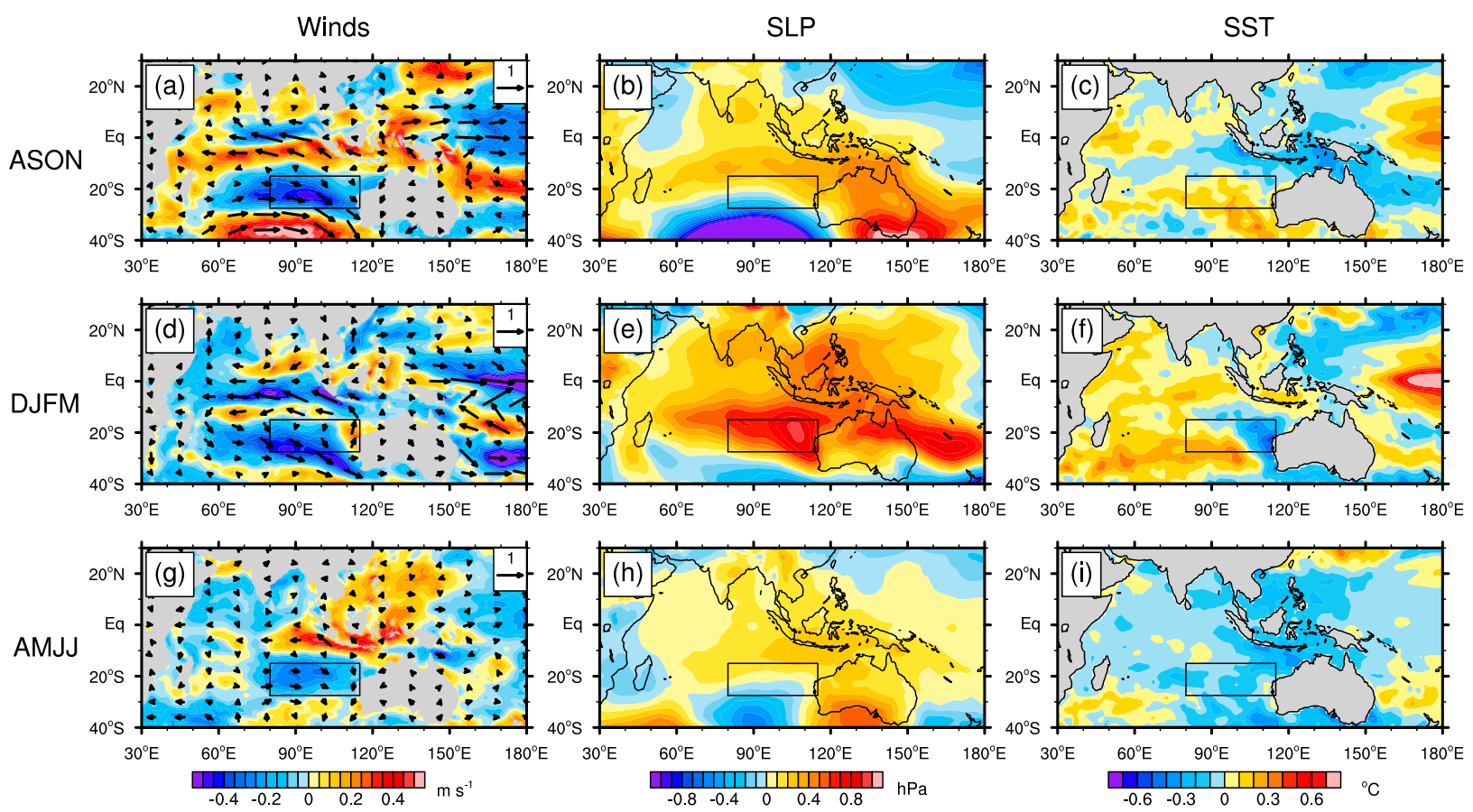

FIG. 12. (left) Surface wind speed, (center) sea level pressure, and (right) SST anomalies regressed onto the net surface heat flux anomalies averaged over the SEIO region $\left(15^{\circ}-27.5^{\circ} \mathrm{S}, 80^{\circ}-115^{\circ} \mathrm{E}\right)$ for (a)-(c) southern spring (August-November), (d)-(f) summer (December-March), and (g)-(i) fall/winter (April-July). Arrows in (a), (d), and (g) illustrate surface wind anomalies regressed onto the same reference index. The reference index was divided by its standard deviation before the regression analysis. The SEIO region is shown by box.

The pair of positive SST anomalies in the southern Indian Ocean $\left(20^{\circ}-35^{\circ} \mathrm{S}, 30^{\circ}-110^{\circ} \mathrm{E}\right)$ and negative SST anomalies west of Australia in summer (Fig. 12f) resembles the pattern of the subtropical Indian Ocean dipole (Behera and Yamagata 2001). Also, negative (positive) SST anomalies in the eastern (western) equatorial Indian Ocean in spring (Fig. 12c) are the pattern of the Indian Ocean dipole (Saji et al. 1999; Webster et al. 1999). However, it is unlikely for these climate modes to take effect. First, the correlation between the indices of these climate modes and the annual-mean surface heat flux anomalies in the SEIO region is significant for the period from 2004 to 2015, but not for the period from 1983 to 2015. Second, the connections are physically unlikely. For the subtropical dipole, Suzuki et al. (2004) showed that surface wind anomalies in $20^{\circ}-30^{\circ} \mathrm{S}$ tend to be easterly when SST anomalies show a pattern like that in Fig. 12f, whereas our results show westerly anomalies there (Fig. 12d). For the tropical Indian Ocean dipole, Yu et al. (2005) showed that its influence on surface winds is restricted to the equatorial area between $10^{\circ} \mathrm{S}$ and $10^{\circ} \mathrm{N}$.

Collectively, the Ningaloo Niño and ENSO are possible contributors to surface heat flux variability in the SEIO region. We cannot specify which climate mode controls surface wind variability in seasons other than southern summer.
Note that contributions from freshwater flux to the generation of spiciness anomalies (red line in Fig. 11a) counteract those from heat flux (blue line in Fig. 11a) in 2009, 2010, 2013, and 2014. In these years, stronger evaporation leads to cooling and salinification of the surface water, the former of which contributes to the production of a negative spiciness anomaly, and the latter to a positive anomaly (Fig. 9). The thermal effect is stronger than the haline effect in the current case, resulting in the production of negative spiciness anomalies. This counteract by the haline effect does not always happen because of precipitation.

\section{Summary and discussion}

Temperature variability in the interior of the ocean is caused by heave of the thermocline and variations in spiciness. The latter is measured by isopycnal variations in $T$ and $S$. This study examined spiciness anomalies in the upper pycnocline of the south Indian Ocean using in situ hydrographic observations, gridded observational datasets and reanalyses. We focused on the period from 2004 to 2015, during which in situ $T / S$ observations are dense (Fig. 1). In almost all aspects, results of the ocean reanalysis agreed well with those from observations. 


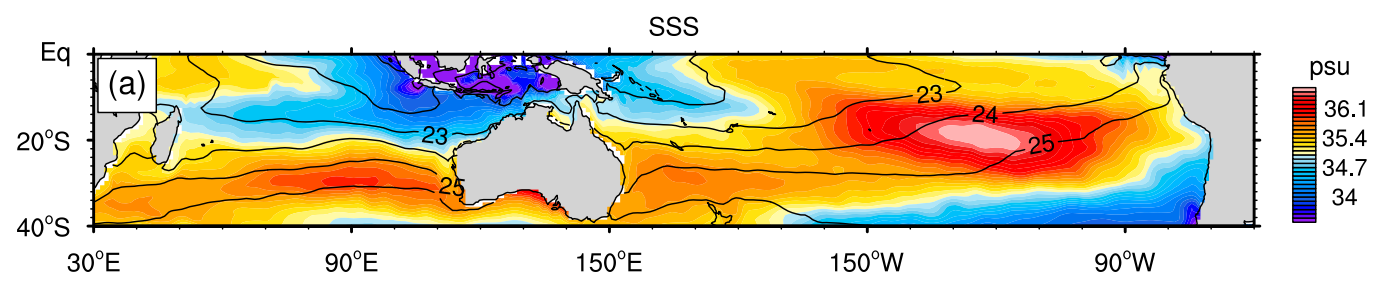

$\partial \theta / \partial \mathrm{S}$

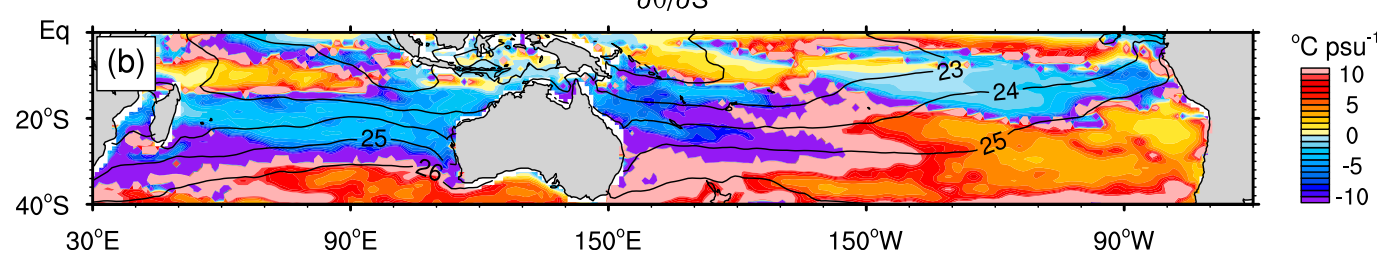

FIG. 13. (a) Salinity and (b) $\partial \theta / \partial S$ at the surface in July. Contours show surface density $\sigma_{\theta}$ in July. Note that $\partial \theta / \partial S$ was calculated as the ratio of the meridional gradient of SST to that of SSS. Results were obtained from ORAS4.

We focused on spiciness anomalies centered at $15^{\circ} \mathrm{S}$ on $25 \sigma_{\theta}$ (Fig. 2), which have a relatively larger contribution to isobaric temperature variability in comparison to thermocline heave (Fig. 3). Spiciness anomalies tend to migrate from east-southeast to west-northwest, being advected by the mean subtropical gyre and form a zonally elongated pattern (Figs. 4 and 5). The upstream end of the spreading path is the southeastern Indian Ocean (Fig. 6), where the $25 \sigma_{\theta}$ surface outcrops in winter. The analysis of the $T / S$ diagram revealed that warming (cooling) of the surface water generates a positive (negative) spiciness anomaly in the outcrop region (Fig. 9). Surface heat flux in the outcrop region was integrated in each year to estimate warming/cooling of the surface water, and the resulting estimate of spiciness anomaly production agreed well with isopycnal SSS anomalies at the outcrop line (Fig. 10). This result indicates that spiciness anomalies are generated by local surface heat flux. Surface freshwater flux also contributes to spiciness anomaly production, but its impact was smaller than that from surface heat flux. The Ningaloo Niño and ENSO contribute to surface heat flux anomalies near the outcrop region via the impacts on trade wind speeds and latent heat flux (Figs. 11 and 12). These climate modes take effect only in southern summer, and we could not specify responsible climate modes in other seasons.

In the Pacific and Atlantic Oceans, spiciness anomalies are generated in the formation area of mode water, where $T$ and $S$ near the surface tend to be density compensating in the horizontal or vertical direction (Johnson 2006). In contrast, spiciness anomalies in the south Indian Ocean examined here are significantly lighter than mode waters and generated in the region where SST and SSS do not tend to be density compensating (Figs. 7 and 8). This peculiarity is likely related to the presence of ITF, which brings freshwater from the Pacific to the south Indian Ocean between $10^{\circ}$ and $20^{\circ} \mathrm{S}$ (Fig. 13a). As a result, SSS decreases to the north between $15^{\circ}$ and $30^{\circ} \mathrm{S}$, giving rise to a wide region with negative $\partial \theta / \partial S$ (Fig. 13b). Such a supply of freshwater from the eastern boundary is absent in the South Pacific, where the region with negative $\partial \theta / \partial S$ is located nearer to the equator in the eastern basin $\left(5^{\circ}-20^{\circ} \mathrm{S}, 80^{\circ}-150^{\circ} \mathrm{W}\right)$ and less exposed to midlatitude subduction.

We found that the surface heat and freshwater flux is directly related to the production of spiciness anomalies in our case. According to our estimates, surface heat flux variability of about $10 \mathrm{~W} \mathrm{~m}^{-2}$ in the outcrop region of the $25 \sigma_{\theta}$ surface leads a spiciness anomaly of about 0.1 psu (Figs. 10 and 11a,b), which is equivalent to a temperature change of about $0.25^{\circ} \mathrm{C}$. The generated spiciness anomalies spread to a wide area in the interior (Figs. 4 and 5). This result means that spiciness variability carries the surface warming/cooling signals to the subsurface ocean, possibly provides a regime for subsurface ocean heat uptake and affects warming rates.

Our results also hint that spiciness anomalies in the south Indian Ocean possibly affect $T / S$ variability at low latitudes. Spiciness anomalies on $25 \sigma_{\theta}$ intrude into the equator along the eastern African coast (e.g., Figs. 4e,k and $5 \mathrm{e}, \mathrm{k}$ ), which may be advected to the Northern Hemisphere by the Somali Current. Schott et al. (2002) reported that water lighter than $25 \sigma_{\theta}$ upwells off Somalia, and it is possible that spiciness anomalies on $25 \sigma_{\theta}$ can be brought to the surface there. The impact of spiciness variability on SST in this region remains for a future study.

Acknowledgments. We thank two anonymous reviewers for their helpful comments. Parts of in situ 

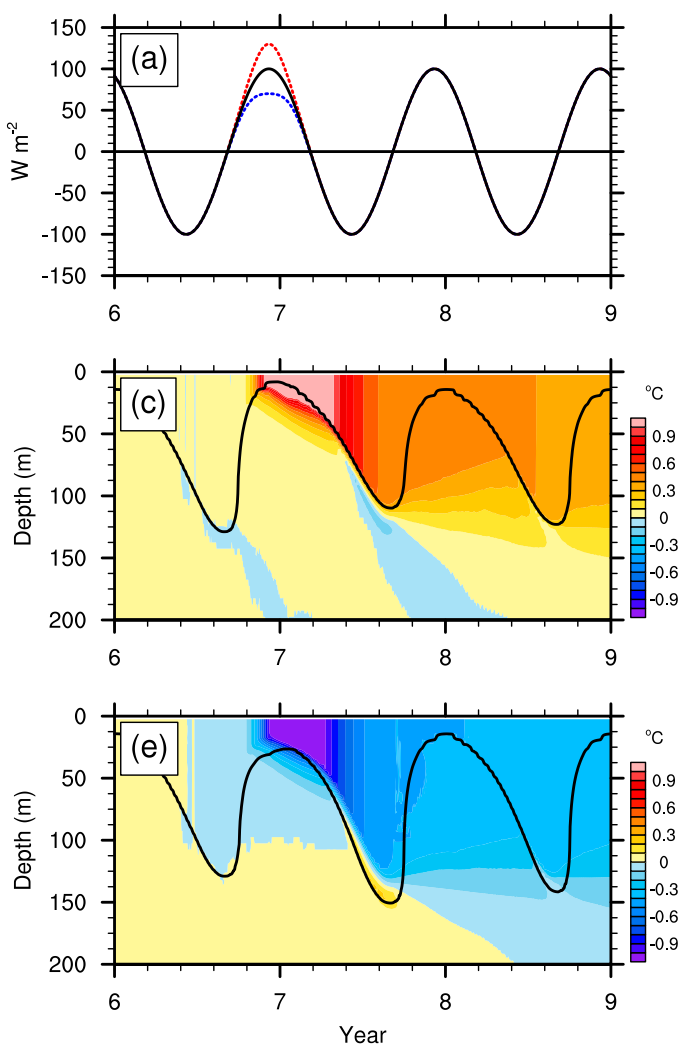
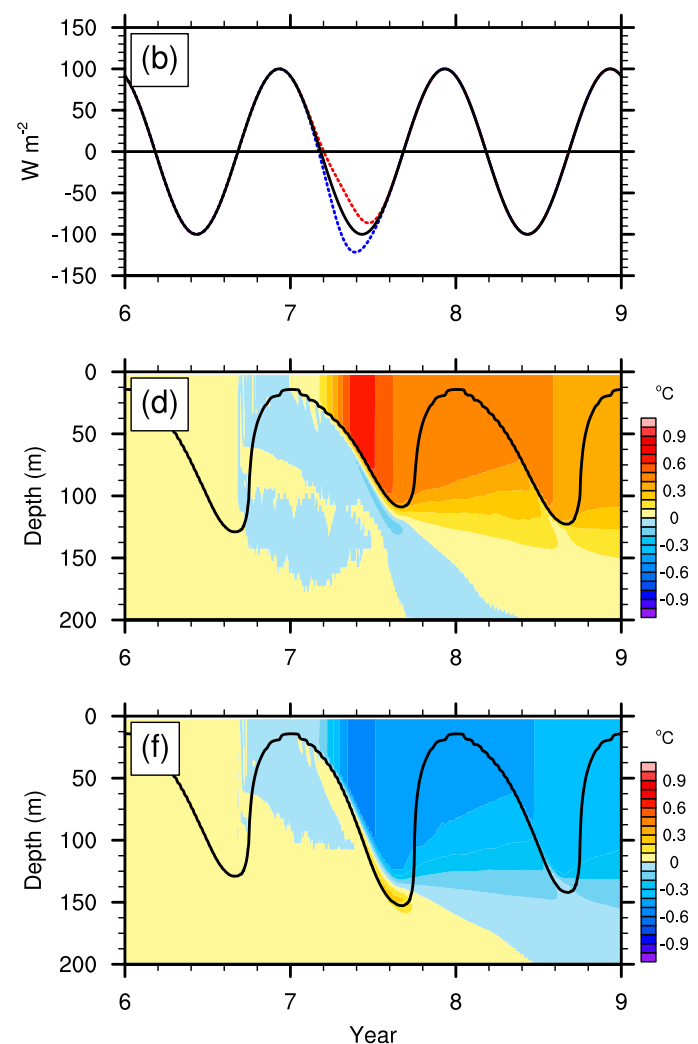

FIG. A1. Results of sensitivity experiments using a 1D mixed layer model. (a),(b) Surface net heat flux for the control run (black solid line) and the sensitivity experiment with warming anomalies (red dotted line) and with cooling anomalies (blue dotted line). Warming/cooling was added in southern summer for (a) and in fall for (b). (c)-(f) Differences of temperature between the control run and the sensitivity experiments (colors). Superposed black solid line shows MLD. An anomalous surface warming (cooling) was applied in the sensitivity experiments for (c) and (d) [(e) and (f)]. Anomalous surface heat flux was applied in southern summer for (c) and (e) and in fall for (d) and (f).

temperature and salinity observations used in this study were collected and made freely available by the International Argo Program and the national programs that contribute to it. (http://www.argo.ucsd.edu and http://argo.jcommops.org). The Argo Program is part of the Global Ocean Observing System.

\section{APPENDIX}

\section{Experiments with a One-Dimensional Mixed Layer Model}

This appendix assesses how anomalous surface heat flux in summer and fall impacts wintertime mixed layer temperature, using a one-dimensional (1D) mixed layer model based on the $K$-profile parameterization scheme (Large et al. 1994). The model domain is the upper $2000 \mathrm{~m}$, and the vertical grid intervals are $5 \mathrm{~m}$ in the top $400 \mathrm{~m}$ and gradually increase to $300 \mathrm{~m}$ to the bottom. The initial conditions for temperature and salinity were obtained from ORAS4 as a January climatology averaged over the region of our interest $\left(25^{\circ} \mathrm{S}, 85^{\circ}-110^{\circ} \mathrm{E}\right)$. The net heat flux and shortwave radiation at the sea surface are imposed as $Q_{\text {net }}=A_{0} \cos \left[2 \pi\left(t+t_{0}\right) / T_{0}\right]$ and $Q_{\text {sw }}=A_{1} \cos \left[2 \pi\left(t+t_{0}\right) / T_{0}\right]+A_{1}^{\prime}$, respectively, where $A_{0}=100 \mathrm{~W} \mathrm{~m}^{-2}, A_{1}=80 \mathrm{~W} \mathrm{~m}^{-2}, A_{1}^{\prime}=180 \mathrm{~W} \mathrm{~m}^{-2}, t$ is time (days), $t_{0}=25$ days, and $T_{0}=365$ days. These parameters were chosen in such a way that the resulting time series mimic monthly climatological surface heat flux obtained from ERA-Interim. No freshwater flux was applied. The model was driven for 10 years. We refer to this as the control run. In sensitivity experiments, the model was run with the same initial and surface boundary conditions, except that heat flux anomaly formulated as $Q_{a}=A_{2} \exp \left\{-\left[\left(t-t_{1}\right) / T_{1}\right]\right\}$ was added to $Q_{\text {net }}$. Here $T_{1}=50$ days. In the first (or second) set of the experiments, $t_{1}$ is set in such a way that $Q_{a}$ is largest in magnitude in southern summer of year 7 (fall of year 7), and 10 different experiments were conducted for $A_{2}$ ranging from -50 to $50 \mathrm{~W} \mathrm{~m}^{-2}$. The time series of $Q_{\text {net }}+Q_{a}$ for $A_{2}= \pm 30 \mathrm{~W} \mathrm{~m}^{-2}$ are shown in Figs. A1a and A1b. 
MLD is defined as the depth where model density is larger than the value at the topmost level by $0.03 \mathrm{~kg} \mathrm{~m}^{-3}$ (solid line in Figs. A1c-f). The mixed layer is thinnest at the end or beginning of year and thickest in midyear, which is similar to the seasonal cycle of MLD in the southeastern Indian Ocean (Fig. 7a), although the 1D model overestimates wintertime MLD $(\sim 130 \mathrm{~m}$ in the model vs $\sim 80 \mathrm{~m}$ in ORAS4). In the $1 \mathrm{D}$ model, there is no mechanism to maintain the stratification, and the stratification set in the initial condition is always eroded in time, resulting in too deep a mixed layer. Nevertheless, the 1D model reproduces the seasonal cycle of MLD well and useful for the current purpose.

The differences in temperature between the control run and the sensitivity experiments reveal how the mixed layer responds to anomalous surface thermal forcing. Anomalous surface warming in summer leads to a rapid increase of mixed layer temperature compared to the control run, which is redistributed to the upper $100 \mathrm{~m}$ in fall (Fig. A1c). The instantaneous increase of mixed layer temperature is smaller when surface warming is applied to fall, because the mixed layer is thicker in fall than in summer (Fig. A1d). However, anomalies of mixed layer temperature are almost the same in magnitude in winter for the two cases, which is the consequence of redistribution of the same amount of heat input to the layer with almost the same thickness. The qualitatively same response occurred in the cases with anomalous surface cooling (Figs. A1e,f).

The above results fit the concept of effective MLD proposed by Deser et al. (2003). We estimated year-toyear changes in wintertime mixed layer temperature from surface heat flux anomalies using Eq. (5). We used a constant MLD of $130 \mathrm{~m}$, which is MLD in the control run in winter of year 6. Also, $Q_{a}$ is used for $Q$ in Eq. (5). For comparison, we calculated the change in mixed layer temperature from 1D model results. Wintertime mixed layer temperature was calculated at the day when the model mixed layer is thickest in each year. We used the difference between the control run and the sensitivity experiment and computed their changes from winter of year 6 to that of year 7 .

Temperature change estimated from surface heat flux agrees well with actual mixed layer temperature variations in the model (Fig. A2). The good agreement is found for both series of the sensitivity experiments, in one of which $Q_{a}$ is applied to summer and the other to fall. The only noticeable discrepancy is the underestimate of temperature increase for the experiments with surface warming anomalies (red marks). This underestimate is about $15 \%$ at most and caused by a thinner mixed layer in the sensitivity experiment owing to stronger surface warming. If we average

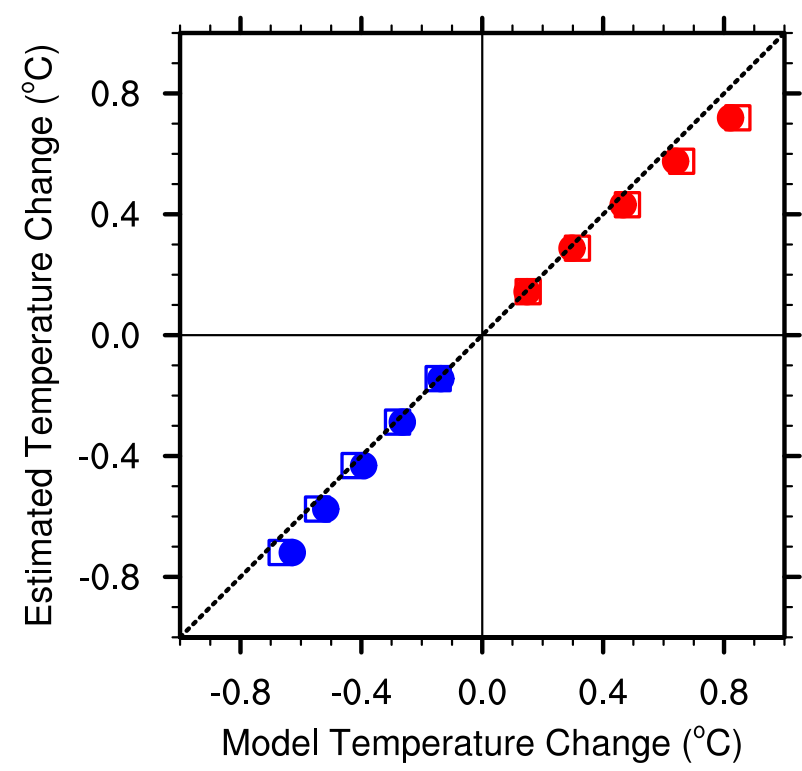

FIG. A2. Comparison of temperature change obtained from 1D model results (horizontal axis) and estimated from anomalous surface heat flux and a constant MLD (vertical axis) from winter in year 6 to that in year 7. Red (blue) marks are for the experiments with anomalous surface warming (cooling). Filled circles (open squares) are for the experiments in which anomalous surface heat flux was added to southern summer (fall). See text for details about how to calculate temperature changes.

model temperature in the upper $130 \mathrm{~m}$ instead of using variable MLD, this underestimate does not happen (figure not shown). Excluding this underestimate, the concept of effective MLD gives an acceptable estimate of temperature variability from one winter to another.

\section{REFERENCES}

Adler, R. F., and Coauthors, 2003: The version-2 Global Precipitation Climatology Project (GPCP) monthly precipitation analysis (1979-present). J. Hydrometeor., 4, 1147-1167, https://doi.org/ 10.1175/1525-7541(2003)004<1147:TVGPCP > 2.0.CO;2.

Alexander, M. A., and C. Deser, 1995: A mechanism for the recurrence of wintertime midlatitude SST anomalies. J. Phys. Oceanogr., 25, 122-137, https://doi.org/10.1175/1520-0485(1995) $025<0122$ :AMFTRO $>2.0 . \mathrm{CO} ; 2$.

Arbic, B. K., and W. B. Owens, 2001: Climatic warming of Atlantic intermediate waters. J. Climate, 14, 4091-4108, https://doi.org/ 10.1175/1520-0442(2001)014<4091:CWOAIW>2.0.CO;2.

Balmaseda, M. A., K. Mogensen, and A. T. Weaver, 2013: Evaluation of the ECMWF ocean reanalysis system ORAS4. Quart. J. Roy. Meteor. Soc., 139, 1132-1161, https://doi.org/10.1002/ qj.2063.

Behera, S. K., and T. Yamagata, 2001: Subtropical SST dipole events in the southern Indian Ocean. Geophys. Res. Lett., 28 327-330, https://doi.org/10.1029/2000GL011451.

Bindoff, N. L., and T. J. McDougall, 1994: Diagnosing climate change and ocean ventilation using hydrographic data. J. Phys. Oceanogr., 24, 1137-1152, https://doi.org/10.1175/ 1520-0485(1994)024<1137:DCCAOV>2.0.CO;2. 
section at $32^{\circ} \mathrm{S}$ and their interpretation. J. Phys. Oceanogr., 30, 1207-1222, https://doi.org/10.1175/1520-0485(2000)030<1207: DCAAIO $>2.0 . \mathrm{CO} ; 2$.

Blanke, B., and S. Raynaud, 1997: Kinematics of the Pacific equatorial undercurrent: An Eulerian and Lagrangian approach from GCM results. J. Phys. Oceanogr., 27, 1038-1053, https://doi.org/10.1175/ 1520-0485(1997)027<1038:KOTPEU>2.0.CO;2.

Boyer, T. P., and Coauthors, 2013: World Ocean Database 2013. S. Levitus, Ed., NOAA Atlas NESDIS 72, 209 pp.

Bretherton, F. P., R. E. Davis, and C. B. Fandry, 1976: A technique for objective analysis and design of oceanographic experiments applied to MODE-73. Deep-Sea Res., 23, 559-582, https://doi.org/10.1016/0011-7471(76)90001-2.

Curry, J. A., and P. J. Webster, 1999: Thermodynamics of Atmospheres and Oceans. Academic Press, 438 pp.

de Boyer Montégut, C., G. Madec, A. S. Fischer, A. Lazar, and D. Iudicone, 2004: Mixed layer depth over the global ocean: An examination of profile data and a profile-based climatology. J. Geophys. Res., 109, C12003, https://doi.org/10.1029/ 2004JC002378.

Dee, D. P., and Coauthors, 2011: The ERA-Interim reanalysis: Configuration and performance of the data assimilation system. Quart. J. Roy. Meteor. Soc., 137, 553-597, https://doi.org/ 10.1002/qj.828.

Deser, C., M. A. Alexander, and M. S. Timlin, 1996: Upperocean thermal variations in the North Pacific during 1970-1991. J. Climate, 9, 1840-1855, https://doi.org/10.1175/ 1520-0442(1996)009<1840:UOTVIT>2.0.CO;2.

,-- , and -2003 : Understanding the persistence of sea surface temperature anomalies in midlatitudes. J. Climate, 16, 57-72, https://doi.org/10.1175/1520-0442(2003)016<0057: UTPOSS $>2.0 . \mathrm{CO} ; 2$.

Domingues, C. M., M. E. Maltrud, S. E. Wijffels, J. A. Church, and M. Tomczak, 2007: Simulated Lagrangian pathways between the Leeuwin Current system and the upper-ocean circulation of the southeast Indian Ocean. Deep-Sea Res., 54, 797-817, https://doi.org/10.1016/j.dsr2.2006.10.003.

Feng, M., M. J. McPhaden, S.-P. Xie, and J. Hafner, 2013: La Niña forces unprecedented Leeuwin Current warming in 2011. Sci. Rep., 3, 1277, https://doi.org/10.1038/srep01277.

Fofonoff, N. P., and R. C. Millard, 1983: Algorithms for computation of fundamental properties of seawater. UNESCO Tech. Paper in Marine Science 44, UNESCO, 53 pp.

Fukumori, I., T. Lee, B. Cheng, and D. Menemenlis, 2004: The origin, pathway, and destination of Niño-3 water estimated by a simulated passive tracer and its adjoint. J. Phys. Oceanogr., 34, 582-604, https://doi.org/10.1175/2515.1.

Giese, B. S., S. C. Urizar, and N. S. Fučkar, 2002: Southern Hemisphere origins of the 1976 climate shift. Geophys. Res. Lett., 29, 1014, https://doi.org/10.1029/2001GL013268.

Goodman, P. J., W. Hazeleger, P. de Vries, and M. Cane, 2005: Pathways into the Pacific equatorial undercurrent: A trajectory analysis. J. Phys. Oceanogr., 35, 2134-2151, https:// doi.org/10.1175/JPO2825.1.

Grenier, M., S. Cravatte, B. Blanke, C. Menkes, A. KochLarrouy, F. Durand, A. Melet, and C. Jeandel, 2011: From the western boundary currents to the Pacific equatorial undercurrent: Modeled pathways and water mass evolutions. J. Geophys. Res., 116, C12044, https://doi.org/10.1029/ 2011JC007477.

Gu, D., and S. G. H. Philander, 1997: Interdecadal climate fluctuations that depend on exchanges between the tropics and extratropics. Science, 275, 805-807, https://doi.org/10.1126/ science.275.5301.805.

Hosoda, S., T. Ohira, and T. Nakamura, 2008: A monthly mean dataset of global oceanic temperature and salinity derived from Argo float observations. JAMSTEC Rep. Res. Dev., 8, 47-59, https://doi.org/10.5918/jamstecr.8.47.

Huffman, G. J., and Coauthors, 1997: The Global Precipitation Climatology Project (GPCP) combined precipitation dataset. Bull. Amer. Meteor. Soc., 78, 5-20, https://doi.org/10.1175/ 1520-0477(1997)078<0005:TGPCPG > 2.0.CO;2.

Johnson, G. C., 2006: Generation and initial evolution of a mode water $\theta-S$ anomaly. J. Phys. Oceanogr., 36, 739-751, https:// doi.org/10.1175/JPO2895.1.

— - and M. J. McPhaden, 1999: Interior pycnocline flow from the subtropical to the equatorial Pacific Ocean. J. Phys. Oceanogr., 29, 3073-3089, https://doi.org/10.1175/1520-0485(1999)029<3073: IPFFTS $>2.0 . \mathrm{CO} ; 2$.

Karstensen, J., and D. Quadfasel, 2002: Water subducted into the Indian Ocean subtropical gyre. Deep-Sea Res., 49, 1441-1457, https://doi.org/10.1016/S0967-0645(01)00160-6.

Kataoka, T., T. Tozuka, S. Behera, and T. Yamagata, 2014: On the Ningaloo Niño/Niña. Climate Dyn., 43, 1463-1482, https:// doi.org/10.1007/s00382-013-1961-z.

Katsura, S., E. Oka, B. Qiu, and N. Schneider, 2013: Formation and subduction of North Pacific tropical water and their interannual variability. J. Phys. Oceanogr., 43, 2400-2415, https://doi.org/10.1175/JPO-D-13-031.1.

Kessler, W. S., 1999: Interannual variability of the subsurface high salinity tongue south of the equator at $165^{\circ} \mathrm{E}$. J. Phys. Oceanogr., 29, 2038-2049, https://doi.org/10.1175/1520-0485(1999)029<2038: IVOTSH $>2.0 . \mathrm{CO} ; 2$.

Kolodziejczyk, N., and F. Gaillard, 2012: Observation of spiciness interannual variability in the Pacific pycnocline. J. Geophys. Res., 117, C12018, https://doi.org/10.1029/2012JC008365.

- and _ 2013: Variability of the heat and salt budget in the subtropical southeastern Pacific mixed layer between 2004 and 2010: Spice injection mechanism. J. Phys. Oceanogr., 43, 18801898, https://doi.org/10.1175/JPO-D-13-04.1.

— G. Reverdin, and A. Lazar, 2015: Interannual variability of the mixed layer winter convection and spice injection in the eastern subtropical North Atlantic. J. Phys. Oceanogr., 45, 504-525, https://doi.org/10.1175/JPO-D-14-0042.1.

Kouketsu, S., S. Osafune, Y. Kumamoto, and H. Uchida, 2017: Eastward salinity anomaly propagation in the intermediate layer of the North Pacific. J. Geophys. Res. Oceans, 122, 15901607, https://doi.org/10.1002/2016JC012118.

Large, W. G., J. C. McWilliams, and S. C. Doney, 1994: Oceanic vertical mixing: A review and a model with a nonlocal boundary layer parameterization. Rev. Geophys., 32, 363-403, https://doi.org/10.1029/94RG01872.

Laurian, A., A. Lazar, G. Reverdin, K. Rodgers, and P. Terray, 2006: Poleward propagation of spiciness anomalies in the North Atlantic Ocean. Geophys. Res. Lett., 33, L13603, https:// doi.org/10.1029/2006GL026155.

, — - and —, 2009: Generation mechanism of spiciness anomalies: An OGCM analysis in the North Atlantic subtropical gyre. J. Phys. Oceanogr., 39, 1003-1018, https://doi.org/10.1175/ 2008JPO3896.1.

Lazar, A., R. Murtugudde, and A. J. Busalacchi, 2001: A model study of temperature anomaly propagation from the subtropics to tropics within the South Atlantic thermocline. Geophys. Res. Lett., 28, 1271-1274, https://doi.org/10.1029/ 2000 GL011418. 
Li, Y., and F. Wang, 2015: Thermocline spiciness variations in the tropical Indian Ocean observed during 2003-2014. Deep-Sea Res., 97, 52-66, https://doi.org/10.1016/j.dsr.2014.12.004.

,$- \ldots$, and Y. Sun, 2012: Low-frequency spiciness variations in the tropical Pacific Ocean observed during 2003-2012. Geophys. Res. Lett., 39, L23601, https://doi.org/10.1029/ 2012GL053971.

Liu, L. L., and R. X. Huang, 2012: The global subduction/obduction rates: Their interannual and decadal variability. J. Climate, 25, 1096-1115, https://doi.org/10.1175/2011JCLI4228.1.

Locarnini, R. A., and Coauthors, 2013: Temperature. Vol. 1, World Ocean Atlas 2013, S. Levitus, Ed., NOAA Atlas NESDIS 73, $40 \mathrm{pp}$.

Lu, P., and J. P. McCreary, 1995: Influence of the ITCZ on the flow of thermocline water from the subtropical to the equatorial Pacific Ocean. J. Phys. Oceanogr., 25, 3076-3088, https://doi.org/ 10.1175/1520-0485(1995)025<3076:IOTIOT>2.0.CO;2.

,$- \ldots$, and B. A. Klinger, 1998: Meridional circulation cells and the source waters of the Pacific equatorial undercurrent. J. Phys. Oceanogr., 28, 62-84, https://doi.org/10.1175/ 1520-0485(1998)028<0062:MCCATS > 2.0.CO;2.

Luo, Y., L. M. Rothstein, R.-H. Zhang, and A. J. Busalacchi, 2005: On the connection between South Pacific subtropical spiciness anomalies and decadal equatorial variability in an ocean general circulation model. J. Geophys. Res., 110, C10002, https://doi.org/10.1029/2004JC002655.

Madec, G., 2008: NEMO reference manual, ocean dynamics component: NEMO-OPA. Preliminary version. Note du Pôle de modélisation 27, IPSL, 209 pp.

Marshall, J. C., A. J. G. Nurser, and R. G. Williams, 1993: Inferring the subduction rate and period over the North Atlantic. J. Phys. Oceanogr., 23, 1315-1329, https://doi.org/10.1175/ 1520-0485(1993)023<1315:ITSRAP>2.0.CO;2.

McDonagh, E. L., H. L. Bryden, B. A. King, R. J. Sanders, S. A. Cunningham, and R. Marsh, 2005: Decadal changes in the South Indian Ocean thermocline. J. Climate, 18, 1575-1590, https://doi.org/10.1175/JCLI3350.1.

Nagura, M., and M. J. McPhaden, 2018: The shallow overturning circulation in the Indian Ocean. J. Phys. Oceanogr., 48, 413434, https://doi.org/10.1175/JPO-D-17-0127.1.

Namias, J., and R. M. Born, 1970: Temporal coherence in North Pacific sea-surface temperature patterns. J. Geophys. Res., $\mathbf{7 5}$, 5952-5955, https://doi.org/10.1029/JC075i030p05952.

— North Pacific sea surface temperatures. J. Geophys. Res., 79, 797-798, https://doi.org/10.1029/JC079i006p00797.

Nonaka, M., and H. Sasaki, 2007: Formation mechanism for isopycnal temperature-salinity anomalies propagating from the eastern South Pacific to the equatorial region. J. Climate, 20, 1305-1315, https://doi.org/10.1175/JCLI4065.1.

O'Kane, T. J., R. J. Matear, M. A. Chamberlain, and P. R. Oke, 2014: ENSO regimes and the late 1970's climate shift: The role of synoptic weather and South Pacific Ocean spiciness. J. Comput. Phys., 271, 19-38, https://doi.org/10.1016/j.jcp.2013.10.058.

Praveen Kumar, B. P., J. Vialard, M. Lengaigne, V. S. N. Murty, and M. J. McPhaden, 2012: TropFlux: Air-sea fluxes for the global tropical oceans-Description and evaluation. Climate Dyn., 38, 1521-1543, https://doi.org/10.1007/ s00382-011-1115-0.

Qu, T., L. Zhang, and N. Schneider, 2016: North Atlantic subtropical underwater and its year-to-year variability in annual subduction rate during the Argo period. J. Phys. Oceanogr., 46, 1901-1916, https://doi.org/10.1175/JPO-D-15-0246.1.
Ren, L., and S. Riser, 2010: Observations of decadal time scale salinity changes in the subtropical thermocline of the North Pacific Ocean. Deep-Sea Res. II, 57, 1161-1170, https://doi.org/ 10.1016/j.dsr2.2009.12.005.

Reynolds, R. W., N. A. Rayner, T. M. Smith, D. C. Stokes, and W. Wang, 2002: An improved in situ and satellite SST analysis for climate. J. Climate, 15, 1609-1625, https://doi.org/10.1175/ 1520-0442(2002)015<1609:AIISAS > 2.0.CO;2.

Rintoul, S. R., and M. H. England, 2002: Ekman transport dominates local air-sea fluxes in driving variability of subantarctic mode water. J. Phys. Oceanogr., 32, 1308-1321, https://doi.org/ 10.1175/1520-0485(2002)032<1308:ETDLAS > 2.0.CO;2.

Rodgers, K. B., B. Blanke, G. Madec, O. Aumont, P. Ciais, and J.-C. Dutay, 2003: Extratropical sources of equatorial Pacific upwelling in an OGCM. Geophys. Res. Lett., 30, 1084, https:// doi.org/10.1029/2002GL016003.

Saji, N. H., B. N. Goswami, P. N. Vinayachandran, and T. Yamagata, 1999: A dipole mode in the tropical Indian Ocean. Nature, 401, 360-363, https://doi.org/10.1038/43854.

Sasaki, Y. N., N. Schneider, N. Maximenko, and K. Lebedev, 2010: Observational evidence for propagation of decadal spiciness anomalies in the North Pacific. Geophys. Res. Lett., 37, L07708, https://doi.org/10.1029/2010GL042716.

Schneider, N., 2000: A decadal spiciness mode in the tropics. Geophys. Res. Lett., 27, 257-260, https://doi.org/10.1029/ 1999GL002348.

— A. J. Miller, M. A. Alexander, and C. Deser, 1999: Subduction of decadal North Pacific temperature anomalies: Observations and dynamics. J. Phys. Oceanogr., 29, 1056-1070, https://doi.org/ 10.1175/1520-0485(1999)029<1056:SODNPT>2.0.CO;2.

Schopf, P. S., and M. J. Suarez, 1988: Vacillations in a coupled oceanatmosphere model. J. Atmos. Sci., 45, 549-566, https://doi.org/ 10.1175/1520-0469(1988)045<0549:VIACOM>2.0.CO;2.

Schott, F. A., M. Dengler, and R. Schoenefeldt, 2002: The shallow overturning circulation of the Indian Ocean. Prog. Oceanogr., 53, 57-103, https://doi.org/10.1016/S0079-6611(02) 00039-3.

— S.-P. Xie, and J. P. McCreary, 2009: Indian Ocean circulation and climate variability. Rev. Geophys., 47, RG1002, https:// doi.org/10.1029/2007RG000245.

Smith, R. L., A. Huyer, J. S. Godfrey, and J. A. Church, 1991: The Leeuwin Current off western Australia. 1986-1987. J. Phys. Oceanogr., 21, 323-345, https://doi.org/10.1175/ 1520-0485(1991)021<0323:TLCOWA > 2.0.CO;2.

Stommel, H., 1979: Determination of water mass properties of water pumped down from the Ekman layer to the geostrophic flow below. Proc. Natl. Acad. Sci. USA, 76, 3051-3055, https:// doi.org/10.1073/pnas.76.7.3051.

Suzuki, R., S. K. Behera, S. Iizuka, and T. Yamagata, 2004: Indian Ocean subtropical dipole simulated using a coupled general circulation model. J. Geophys. Res., 109, C09001, https:// doi.org/10.1029/2003JC001974.

Tatebe, H., Y. Imada, M. Mori, M. Kimoto, and H. Hasumi, 2013: Control of decadal and bidecadal climate variability in the tropical Pacific by the off-equatorial South Pacific Ocean. J. Climate, 26, 6524-6534, https://doi.org/10.1175/JCLI-D-12-00137.1.

Toyoda, T., and Coauthors, 2017: Intercomparison and validation of the mixed layer depth fields of global ocean syntheses. Climate Dyn., 49, 753-773, https://doi.org/10.1007/ s00382-015-2637-7.

Trenberth, K. E., 1997: The definition of El Niño. Bull. Amer. Meteor. Soc., 78, 2771-2778, https://doi.org/10.1175/1520-0477(1997) $078<2771$ :TDOENO $>2.0 . \mathrm{CO} ; 2$. 
Tsubouchi, T., T. Suga, and K. Hanawa, 2010: Indian Ocean subtropical mode water: Its water characteristics and spatial distribution. Ocean Sci., 6, 41-50, https://doi.org/10.5194/os-6-41-2010.

Wallace, J. M., E. M. Rasmusson, T. P. Mitchell, V. E. Kousky, E. S. Sarachik, and H. von Storch, 1998: On the structure and evolution of ENSO-related climate variability in the tropical Pacific: Lessons from TOGA. J. Geophys. Res., 103, $142241-$ 142 259, https://doi.org/10.1029/97JC02905.

Webster, P. J., A. M. Moore, J. P. Loschnigg, and R. R. Leben, 1999: Coupled ocean-atmosphere dynamics in the Indian Ocean during 1997-98. Nature, 401, 356-360, https://doi.org/10.1038/43848.

Wijffels, S., J. Sprintall, M. Fieux, and N. Bray, 2002: The JADE and WOCE I10/IR6 Throughflow sections in the southeast Indian Ocean. Part 1: Water mass distribution and variability. Deep-Sea Res., 49, 1341-1362, https://doi.org/10.1016/ S0967-0645(01)00155-2.

Williams, R. G., 1991: The role of the mixed layer in setting the potential vorticity of the main thermocline. J. Phys. Oceanogr., 21,
1803-1814, https://doi.org/10.1175/1520-0485(1991)021<1803: TROTML $>2.0 . \mathrm{CO} ; 2$.

Woods, J. D., 1985. Physics of thermocline ventilation. Coupled Ocean-Atmosphere Models, J. C. J. Nihoul, Ed., Elsevier, 543-590.

Yeager, S. G., and W. G. Large, 2004: Late-winter generation of spiciness on subducted isopycnals. J. Phys. Oceanogr., 34, 1528-1547, https://doi.org/10.1175/1520-0485(2004)034<1528: LGOSOS $>2.0 . \mathrm{CO} ; 2$.

$\mathrm{Yu}, \mathrm{L}$., and R. A. Weller, 2007: Objectively analyzed air-sea heat fluxes for the global oceans (1981-2005). Bull. Amer. Meteor. Soc., 88, 527-539, https://doi.org/10.1175/BAMS-88-4-527.

Yu, W., B. Xiang, L. Liu, and N. Liu, 2005: Understanding the origins of interannual thermocline variations in the tropical Indian Ocean. Geophys. Res. Lett., 32, L24706, https://doi.org/ 10.1029/2005GL024327.

Zweng, M. M., and Coauthors, 2013: Salinity. Vol. 2, World Ocean Atlas 2013, S. Levitus, Ed., NOAA Atlas NESDIS 74, 39 pp. 